\title{
El almacén anfórico del barrio de El Molinete en Carthago Spartaria (Cartagena): un nuevo contexto cerámico del siglo VII en la Hispania bizantina
}

\author{
An amphorae warehouse in El Molinete, Carthago \\ Spartaria (Cartagena): a new 7th pottery context \\ in Byzantine Hispania
}

\author{
JAIME VIZCAÍNO SÁNCHEZ \\ Universidad de Murcia. Departamento de Prehistoria, Arqueología, Historia Antigua, \\ Historia Medieval y Ciencias y Técnicas Historiográficas \\ C/ Santo Cristo, 1, E-30001 Murcia, \\ javisa@um.es
}

\author{
José Miguel Noguera Celdrán \\ Universidad de Murcia. Departamento de Prehistoria, Arqueología, Historia Antigua, \\ Historia Medieval y Ciencias y Técnicas Historiográficas \\ C/ Santo Cristo, 1, E-30001 Murcia, \\ noguera@um.es
}

\author{
María José MADrid BALANZA \\ Universidad de Murcia. Departamento de Prehistoria, Arqueología, Historia Antigua, \\ Historia Medieval y Ciencias y Técnicas Historiográficas \\ C/ Santo Cristo, 1, E-30001 Murcia, \\ mariajosemadridbalanza@gmail.com
}

Las excavaciones en el pie de la ladera suroriental en el cerro de El Molinete (Cartagena, España; Hispania Carthaginiensis) están incrementando nuestro conocimiento acerca de la ocupación protobizantina de Carthago Spartaria. Analizamos el nivel de abandono de un almacén construido en el interior de un antiguo edificio romano (un antiguo Iseum) ya amortizado y transformado. A pesar de sus pequeñas dimensiones, el almacén contenía 16 ánforas de la región de Túnez, Ibiza o el Mediterráneo oriental. Este nuevo depósito puede fecharse en el primer cuarto del siglo viI. El conjunto enfatiza las fuertes relaciones entre Hispania y el norte de África durante los siglos VI y VII. 
The archaeological excavations at the foot of the southeast slope of El Molinete (Cartagena, Spain; Hispania Carthaginiensis) are increasing our knowledge about the early Byzantine occupation of Carthago Spartaria. Here, we analyse the abandonment level of a warehouse built into a dismantled and metamorphosed Roman monumental building, the old Iseum. Despite its small dimensions, this warehouse contained 16 amphorae from the Tunisian region, Ibiza or Eastern Mediterranean. This new deposit can be dated to the first quarter of the $7^{\text {th }}$ century. The assemblage emphasizes the close relationship between Hispania and North Africa between $6^{\text {th }}$ and $7^{\text {th }}$ centuries.

\section{KEYWORDS}

ARX HASDRUBALIS, CARTHAGO SPARTARIA, EARLY BYZANTINE, WAREHOUSE, AMPHORAE, $7^{\mathrm{TH}}$ CENTURY

\section{Introducción*}

Las investigaciones arqueológicas desarrolladas desde el año 2008 en el Parque Arqueológico del Molinete y en particular en el cerro homónimo (la acrópolis o arx Hasdrubalis referida por Polibio [X 10,9]), ${ }^{1}$ están ayudando a redefinir el conocimiento de las diversas etapas históricas de Cartagena (Noguera y Madrid, 2010; Noguera et al., 2016) (fig. 1). El cerro y sus áreas adyacentes ocupan un lugar central en la topografía urbana y han desempeñado un papel clave en la historia de la ciudad desde época púnica hasta el mismo siglo xx. De gran interés son los datos sobre la ocupación romana del lugar, configurado como un barrio encajado entre el puerto y el foro de la colonia. Este conoció entre los siglos II a. C. y III d. C. un especial desarrollo, revelándose de importancia capital para el estudio de los procesos de desarrollo y monumentalización urbana y arquitectónica de la Carthago Nova de épocas republicana y altoimperial (Noguera y Madrid, 2014). Hasta la fecha se han documentado cuatro ínsulas en las que durante el siglo i d. C. fueron construidos algunos de los edificios más significativos de la colonia, como las Termas del Puerto (Madrid et al., 2015), el Edificio del Atrio —quizá la sede de una hipotética corporación colegial (Noguera et al., 2016)—, o el santuario de la Insula II consagrado al culto de la gens isiaca (Noguera et al., 2019); a ello cabe sumar el área septentrional del foro colonial, bajo cuya terraza superior se ha localizado un barrio tardorrepublicano de los siglos II-I a. C. (Noguera et al., 2018, 63-101). De igual interés ha sido el registro de las vicisitudes y progresivos cambios, abandonos o transformaciones que la zona y sus edificios experimentaron con el tiempo, pues se erigen en un eficaz termómetro para la correcta comprensión de la secuencia histórica de la ciudad a partir de los siglos II-III d. C. (Noguera et al., 2017).

* Este trabajo se enmarca en el proyecto de I+D+i titulado Exemplum et spolia. El legado monumental de las capitales provinciales romanas de Hispania. Perduración, reutilización y transformación en Carthago Nova, Valentia y Lucentum (HAR2015-64386-C4-2-P), financiado por el Ministerio de Ciencia, Innovación y Universidades del Gobierno de España.

1. Sobre el Parque Arqueológico del Moliente: Noguera y Madrid, 2010; Noguera et al., 2016 y 2019; para la ciudad romana: Noguera y Madrid, 2010; Ramallo, 2011; Noguera y Madrid, 2014, 13-60; sobre la ciudad bizantina: Ramallo, 2000, y Vizcaíno, 2009, 224-236, así como, centrándose en las novedades de la colina del Molinete, Vizcaíno et al., e.p. 


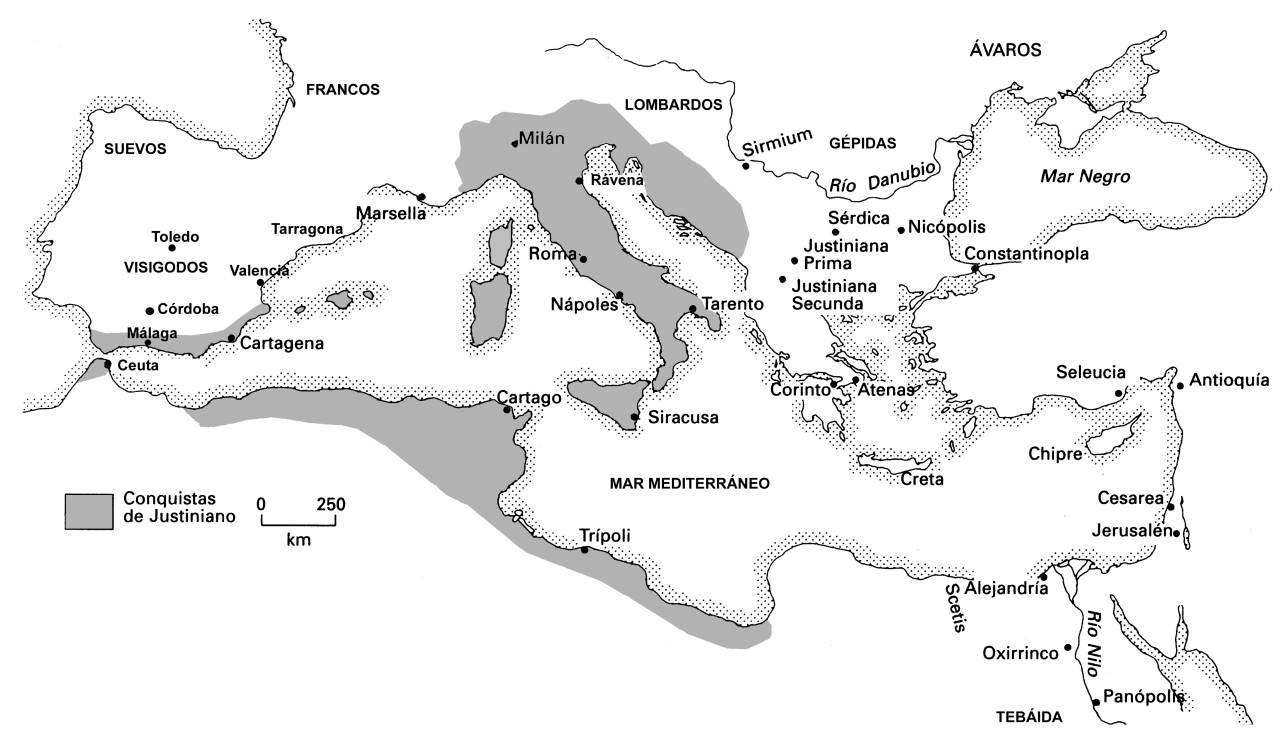

Figura 1. Carthago Spartaria en el marco de la expansión justinianea (Vizcaíno, 2009, fig.1).

De manera particular, sin menoscabo de otras etapas históricas, la ocupación bizantina de El Molinete está proporcionando datos esenciales para la comprensión de la historia material de esta etapa, con frecuencia esquiva en el registro arqueológico (Ramallo y Vizcaíno, 2002). A tenor de lo excavado, este período constituye el colofón de una cadena de intensos cambios que acabaron plasmándose en un populoso barrio artesanal edificado sobre el que, siglos antes, fue uno de los barrios más emblemáticos de época imperial. Lo público dejó paso a lo privado, en un complejo y gradual proceso de reciclaje y reutilización de espacios, ambientes y materiales que ilustran la metamorfosis que Carthago Spartaria experimentó en estas centurias (Vizcaíno, 2018) (fig. 2). Así, al igual que el teatro augusteo acogió un barrio de época bizantina (Ramallo, 2000), esta área adyacente al foro se convirtió igualmente bajo el dominio de los milites romani en asiento de otro complejo habitacional. Cobijado en el armazón proporcionado por algunos de los antiguos edificios altoimperiales, este barrio compartimentó y refuncionalizó sus ambientes con viviendas, talleres y almacenes, desdibujando la trama urbana de la urbe clásica. Dichos cambios solo pueden entenderse en el contexto de una transformación, tan gradual como intensa, que llevó a la ciudad a replegarse sobre la mitad occidental de su primitivo recinto, pasando de 40 a 20 ha de extensión, en un espacio abierto al puerto entre los cerros de La Concepción y El Molinete (Ramallo et al., 2010: 233-247). El sector oriental otrora habitado quedó en cambio abandonado o, en su flanco suroriental, convertido en un extenso cementerio extraurbano, activo entre los siglos v y viI d. C. (Madrid y Vizcaíno, 2009). Las excavaciones efectuadas en la cima del cerro de El Molinete han permitido incluso documentar las primeras trazas de la muralla que en este período constreñía el reducido perímetro urbano (Vizcaíno et al., 2019), que hasta ahora era 


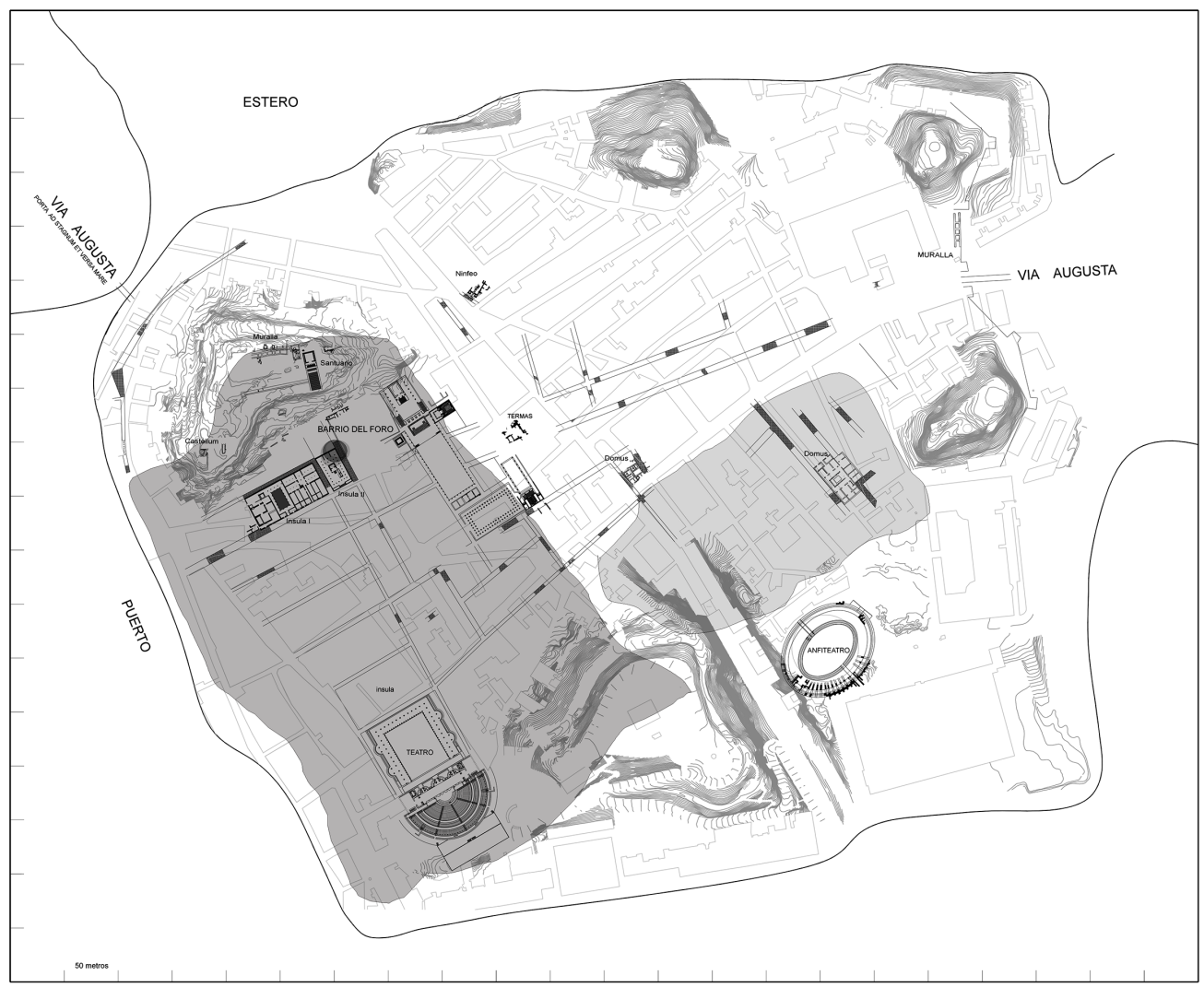

Figura 2. Recinto habitado y necrópolis de época tardía (siglos v-vii) delimitados sobre la planta arqueológica de Cartagena en época altoimperial. En la ladera de El Molinete, dentro del Iseo, se señaliza el lugar del almacén de época bizantina.

solo conocida por la célebre inscripción del magister militum Comitiolus, datada entre septiembre de 589 y agosto de 590 (Abascal y Ramallo, 1997: 447-450, n. ${ }^{\circ} 208$ ).

El objetivo de este trabajo es presentar y contextualizar un ambiente singular de este nuevo barrio artesanal de los siglos VI-VII identificado al pie de El Molinete: se trata de un almacén de este período construido sobre los restos ya amortizados del antiguo Iseum. Su estructura arquitectónica permite que nos adentremos en la configuración de este género de instalaciones y su imbricación en su correspondiente trama urbana, en tanto que su depósito cerámico consiente profundizar en la dinámica comercial de la Hispania suroriental bajo dominio bizantino y, en particular, en los problemas de índole cronológica de ciertas producciones cerámicas. Dicho depósito (fig. 3) se compone de más de una quincena de ánforas, sobre todo pertenecientes a diversas variantes de los tipos tunecinos Keay 61 y 62, junto a otros envases de procedencia oriental, ibicenca o, presumiblemente, local. Fueron documentados aplastados sobre el suelo, añadiendo nuevos datos acerca de los 
Figura 3. Vista aérea de la UE 35426 perteneciente al almacén de época bizantina.

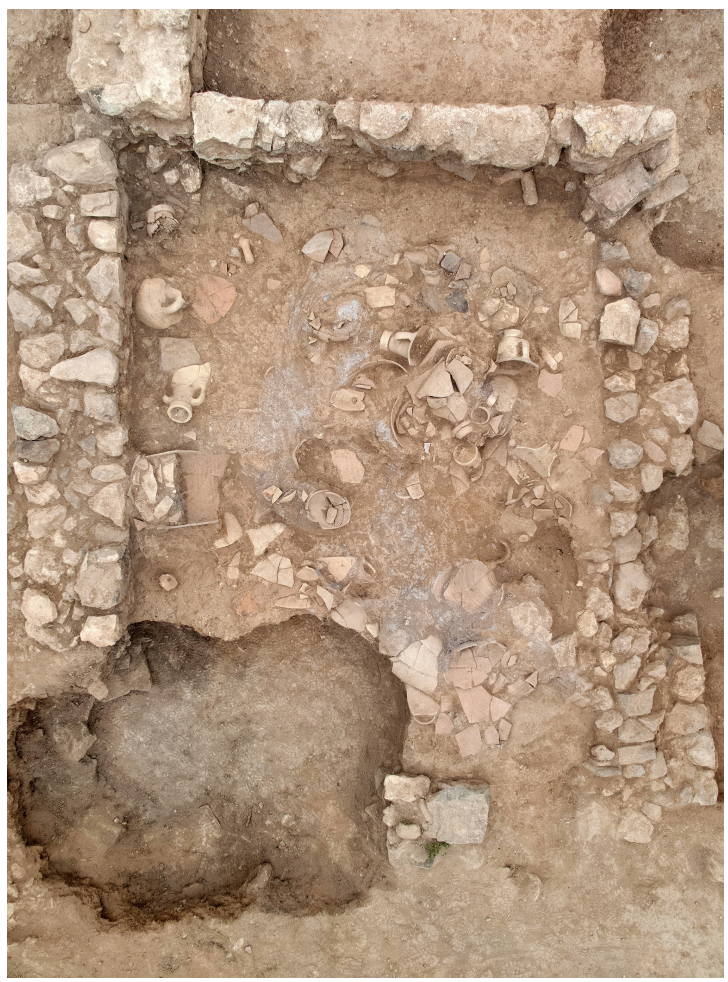

controvertidos contextos asociados a la destrucción de la ciudad por el rey visigodo Suintila (Isid. Hisp., Etym. XV, I, 67-68). Por demás, el hecho de que Cartagena, por su condición de puerto geoestratégico, haya estado secularmente orientada a la actividad comercial y que una de las constantes de su urbanismo desde época púnica haya sido la presencia de espacios de almacenaje (Ramallo y Vizcaíno, 2011), sitúa este nuevo hallazgo como un nuevo y revelador testimonio de los complejos cambios operados en su secuencia histórica.

\section{El área de El Molinete: un sector urbano en constante transformación}

Como se ha referido, la trama urbana y los edificios de época altoimperial de la arx Hasdrubalis experimentaron entre los siglos III y vII d. C. una serie de importantes cambios y transformaciones que prueban el carácter profundamente resiliente de Cartagena en el devenir de su historia. El santuario de Isis y Serapis construido en la Insula II ocupa un lugar preeminente para hilar este discurso. Junto con el Edificio del Atrio (Insula I), es un con- 


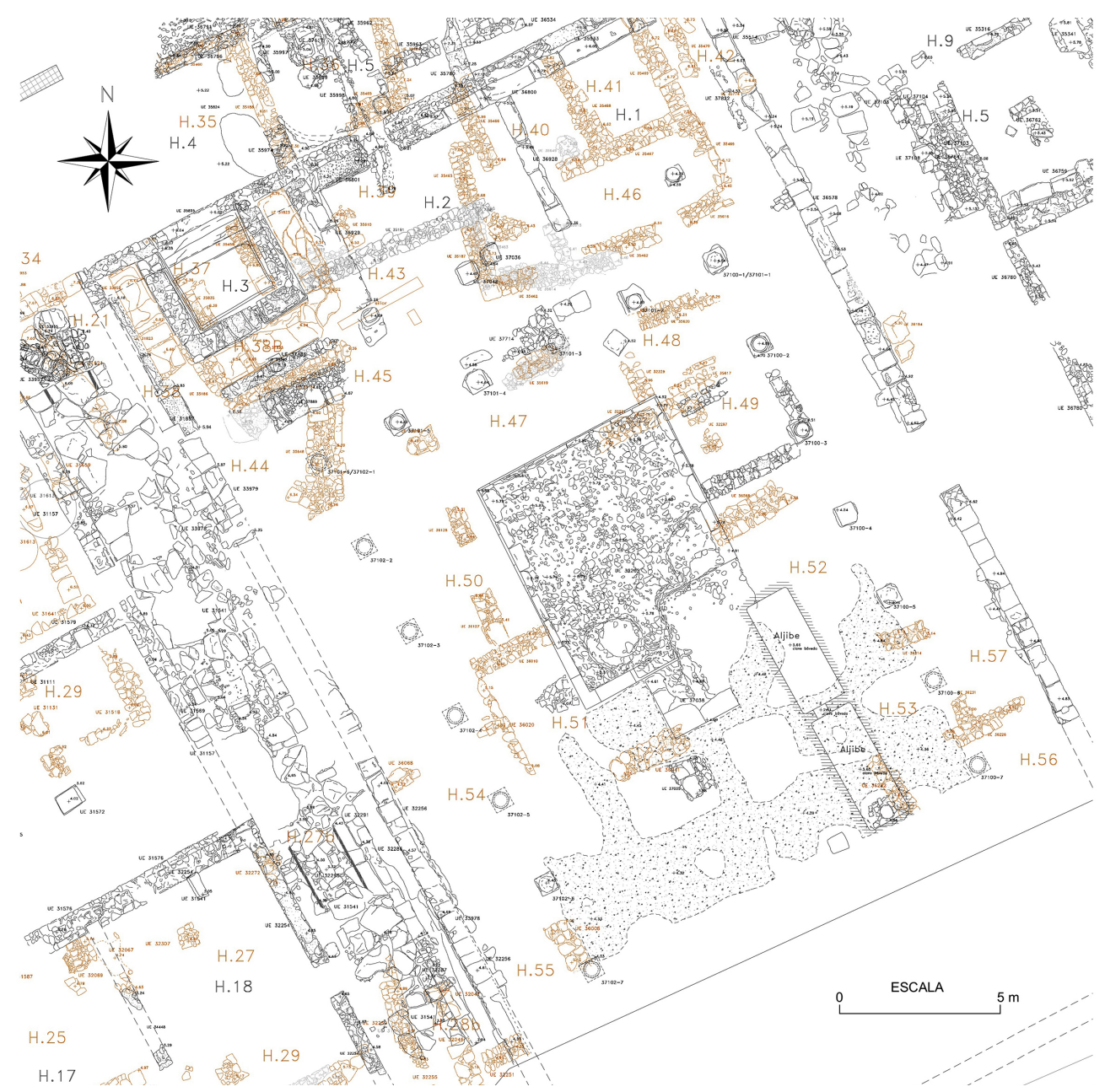

Figura 4. Planta del sector del barrio de época bizantina levantado sobre el antiguo Iseo (dibujo arqueológico: A. Sánchez López; topografía y CAD: José G. Gómez Carrasco).

junto excepcional para el estudio de la topografía religiosa de Carthago Nova y su ambiente cultural sincrético (Noguera et al., 2019). Con el cese de su actividad cultual en un momento indeterminado del siglo III d. C., su abandono y expolio se prolongó de manera intensa en épocas bajoimperial y tardoantigua. En el siglo iv d. C. el recinto fue ocupado por talleres dedicados al trabajo del vidrio y al forjado del hierro, activos hasta la primera mitad del siglo v d. C. (García y Velasco, 2019). A partir de este momento, el antiguo santuario cobijó nuevas unidades domésticas y artesanales que, en progresivo abigarramiento, acabarían configurando durante los siglos vi y viI d. C. un compacto barrio (Vizcaíno, 2019) (fig. 4). 
Aunque las fases de ocupación en épocas moderna y contemporánea han afectado intensamente la conservación de estos niveles tardíos, se ha podido caracterizar una trama urbana que, vertebrada en torno a tres terrazas adaptadas al desnivel del piedemonte suroriental del cerro, incluye al menos 16 habitaciones. Lamentablemente, dicho estado de conservación y la misma irregularidad de las estancias dificultan la individualización de conjuntos arquitectónicos y la definición de sus arterias de tránsito y comunicación. Con todo, parece clara la existencia de un nuevo eje de circulación de tierra batida que, como una suerte de decumano, discurre irregularmente en sentido este-oeste enlazando los antiguos cardines I y II, también desdibujados. Dicho camino, que surge en la parte posterior del arruinado podium del templo isiaco - también ocupado por algunas habitaciones- daba acceso al almacén objeto de análisis. El camino era de trazado irregular, con continuos retranqueos y quiebres a causa del flanqueo de las diversas habitaciones del barrio. Su anchura era decreciente, lo que dificultaría el tránsito rodado; así, si en la parte occidental tiene una anchura de ca. 3,20 m, en su extremo oriental, justo en la zona de acceso al almacén, su anchura transitable es de apenas 1,80 m. Cabe notar, por consiguiente, que el eje apenas reúne los requisitos mínimos para prestar servicio a una instalación como el almacén, máxime cuando su depósito se nutre en particular de grandes contenedores de hasta ca. 80 l, cuyo traslado y manipulación exigirían unos mínimos requisitos espaciales para su transporte y manipulación.

\section{El almacén de época bizantina: caracteres constructivos y de almacenaje}

El almacén documentado se configura como un conjunto de tres habitaciones cobijadas en la esquina nororiental del antiguo iseo (fig. 5). Hasta tal punto las estructuras altoimperiales continúan presentes en la nueva trama urbana que, de hecho, el muro trasero del antiguo temenos (UE 35553) sirve de cierre septentrional a dos de las estancias, habitaciones n. ${ }^{\circ} 40$ y 41 , esta última asimismo separada por un estrecho corredor (hab. n. ${ }^{\circ} 42$ ) del muro oriental del primitivo recinto sacro (UE 35514). Adyacente al almacén por su lado oriental, la estancia n. ${ }^{\circ} 39$, un posible espacio abierto que comunicaba con las habitaciones de la terraza superior, fosilizaba la planta de la antigua capilla central de la cabecera norte del santuario. Estos dos espacios, el corredor n. ${ }^{\circ} 42$ y el patio n. ${ }^{\circ} 39$, contribuirían en cierto modo a delimitar el conjunto, pese a la pauta dominante de yuxtaposición de espacios. En el caso del primero (n. ${ }^{\circ} 42$ ), es posible interpretarlo como corredor por varios factores; entre ellos, cabe referir su posición perimetral, encajado entre el muro lateral (UE 35469) de las habitaciones n. ${ }^{\circ} 41$ y 46 , por el lado occidental, y el muro del antiguo témenos (UE 35514), por el lado oriental. Esta ubicación le depara una morfología peculiar, a modo de pasillo angosto y algo profundo, con unas dimensiones de 1,55 $\mathrm{m}$ ancho por 6,24 $\mathrm{m}$ de 


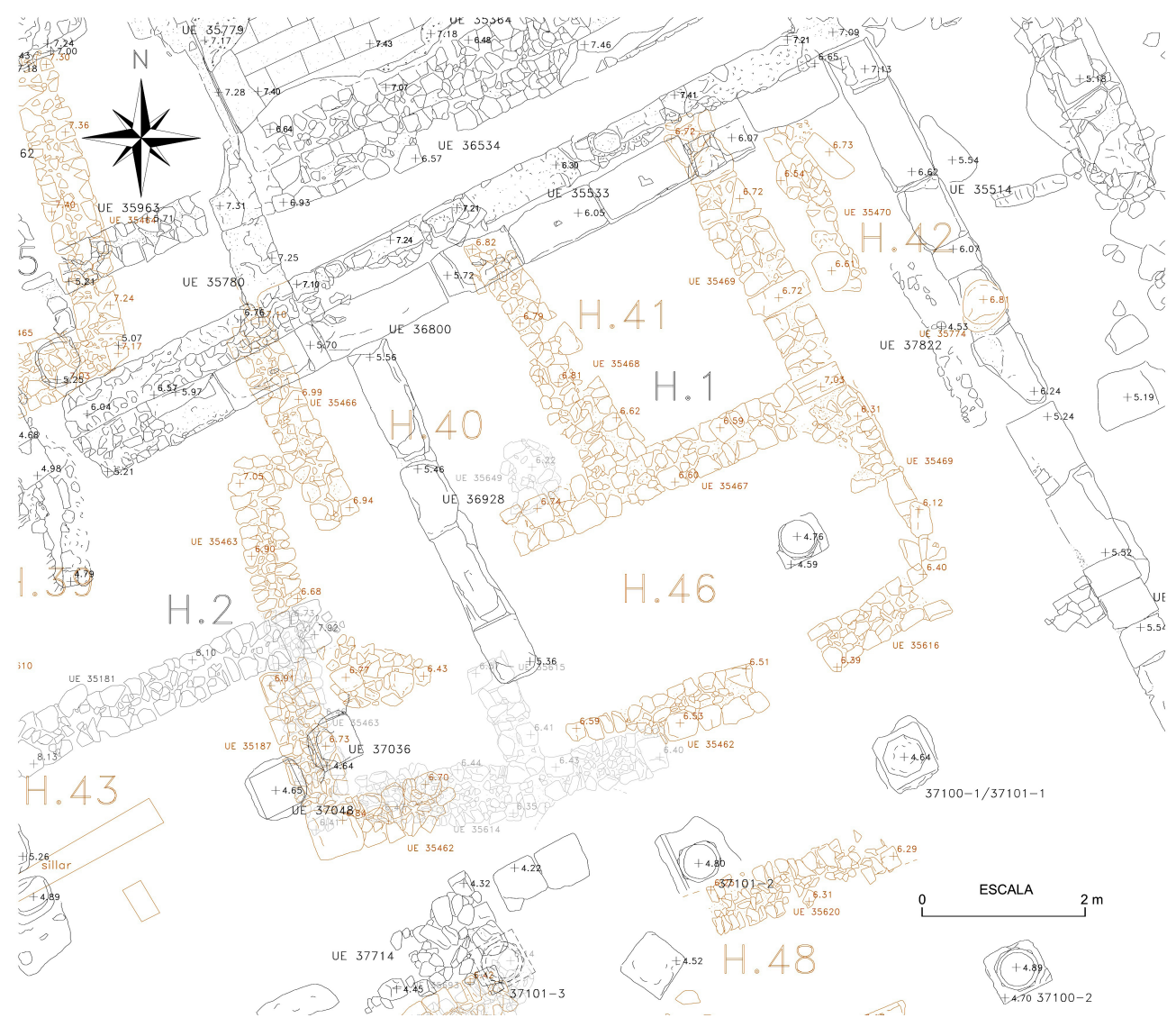

Figura 5. Planta del almacén de época bizantina de la arx Hasdrubalis (dibujo arqueológico: A. Sánchez López ; topografía y CAD: José G. Gómez Carrasco).

largo. En su fondo se sitúa una estructura de escaso alzado (UE 35470) sobre cuya función es difícil pronunciarse.

En consecuencia, el almacén está integrado por tres estancias $\left(n .^{\circ} 46,40\right.$ y 41$)$ que, en conjunto, adoptan una morfología trapezoidal. La estancia n. ${ }^{\circ} 46$ actuaría de módulo de ingreso por medio de un vano abierto en el extremo oriental de su muro meridional (UE 35462). Se trata de un espacio rectangular, posiblemente cubierto, con unas dimensiones de 7,11 m de largo por 2,20 m de ancho. Al norte está delimitado por un muro (UE 35467) desde cuya esquina occidental se accedería al almacén-depósito propiamente dicho (hab. n. $\left.{ }^{\circ} 40\right)$. Si consideramos la disposición de los vanos, puede hablarse de una circulación en «L» o acodada. El almacén estaba cerrado al norte por el viejo muro perimetral del santuario altoimperial (UE 35553), apoyo asimismo de sus paramentos occidental (UE 35466) y 


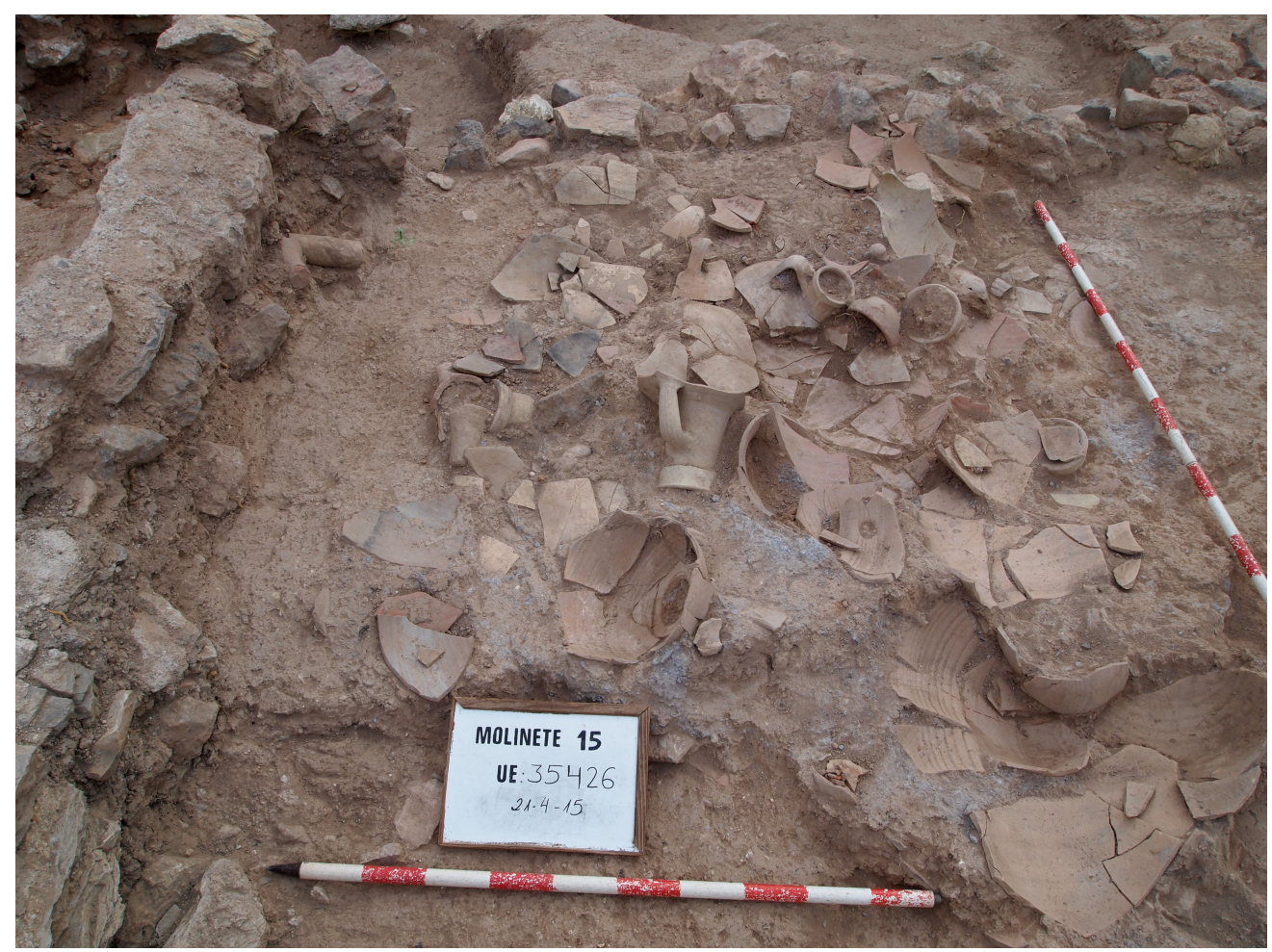

Figura 6. Detalle de la UE 35426 perteneciente al almacén de época bizantina.

oriental (UE 35468). Este último es, además, medianero con la habitación n. ${ }^{\circ} 41$. Ambas estancias aledañas tienen plantas muy similares; la n. ${ }^{\circ} 40$ es prácticamente cuadrangular, con 2,60 m de lado, y la n. ${ }^{\circ} 41$ es rectangular, con 3,38 m de largo y 2,11 m de ancho.

En cuanto a la construcción, siguiendo la tónica constatada en otros sectores del barrio bizantino de la antigua arx Hasdrubalis, los muros se alzaron con mampostería realizada con piedras de pequeño y mediano tamaño trabadas con barro. Su grosor oscila entre 0,50 y $0,70 \mathrm{~m}$, suficiente para soportar el peso de las techumbres, que a tenor de los restos hallados en los niveles de derrumbe (fig. 6) estarían realizadas con ramaje recubierto de los típicos esquistos grisáceos y violáceos de la zona, utilizados como aislantes. Las tres habitaciones comparten también pavimentos de tierra apisonada. En el caso concreto de la habitación n. ${ }^{\circ}$ 40, su suelo (UE 35472) es de tierra compactada con pequeñas piedras, filitas, fragmentos de cal o cerámica. Solo se recuperaron dos pequeños fragmentos expoliados y reutilizados de mármol de tipo greco scritto, empleado con profusión en la decoración de los edificios de la zona en época altoimperial. Su tamaño y posición en el suelo de la estancia revelan que no desempeñaron papel alguno a modo de posible banco de apoyo o revestimiento, sino de mero aglutinante. 
La función de almacenaje de este conjunto no determina un patrón constructivo distinto al del resto de viviendas y talleres del entorno. Dicho de otra manera, a priori no es factible la individualización de pautas constructivas atendiendo a la funcionalidad de las estructuras. El suelo de tierra batida, los alzados de piedra y barro o las cubiertas de ramaje y filitas revelan la ausencia de las preceptivas condiciones de impermeabilidad o estanqueidad propias de estas instalaciones, descartando la posibilidad de guardar productos perecederos. En la misma dirección, la ubicación del almacén en la esquina nororiental de la antigua Insula II, y por tanto su cercanía al desnivel que marca el cambio de terrazas en esta parte inferior de la ladera sureste del cerro, lo sitúa en una zona potencial de escorrentías, con todo lo que ello supondría de humedad.

Una cuestión aún no resuelta es la relativa a la modalidad de almacenaje/apilamiento de los contenedores anfóricos. Téngase en cuenta que en su mayoría se trata ánforas de gran tamaño dotadas de su correspondiente pivote, que no les proporciona una sustentación per se. Al respecto, diferentes paralelos muestran sendos modos de proceder. En la costa palestina conocemos almacenes con suelos pétreos donde una capa de arena, al igual que en las bodegas de los barcos, favorecía la estabilidad de los contenedores. Ocurre así, por ejemplo, en un almacén en el puerto de 'Ard el-Mihjar, al sur de Askelon, donde la tipología de los envases y los hallazgos numismáticos muestran su actividad hasta principios del siglo viI d. C. (Fabian y Goren, 2001). Otro caso es el de los almacenes portuarios de Classe. En este puerto adriático, en un contexto de finales del siglo v d. C. (almacén n. ${ }^{\circ}$ 17), las ánforas se apilaban verticalmente, insertando sus pivotes en una especie de tarima lígnea perforada (Augenti y Cirelli, 2010: 608, fig. 12). No obstante, es preciso extremar la prudencia a la hora de extrapolar soluciones, pues la entidad del suburbio portuario de Rávena y, en concreto, la del contexto referido, que albergaba en el momento de su incendio 180 grandes ánforas junto a 200 spatheia y otras tantas mercancías, tal vez informe solo sobre modalidades de almacenamiento propias de conjuntos especializados de gran entidad. En todo caso, el entarimado lígneo, no necesariamente perforado, se constata en otros almacenes anfóricos más modestos, como vemos por ejemplo en el fuerte de la ciudad protobizantina de Capidava, en la Scythia Minor, fechado a finales del siglo vi d. C. (Opriș y Rațiu: 2016). Sin embargo, en el almacén de Carthago Spartaria no hemos podido documentar trazas sobre estas modalidades de almacenaje y custodia de los contenedores.

Por otro lado, también es necesario discriminar entre los diferentes tipos de almacén. En el caso del referido de Gaza, los ejemplares fueron hallados in situ, aún en pie, y además conservaban sus opérculos e incluso trazas de residuos, todo lo que indica que estaban intactos, preparados para su exportación desde el cercano puerto (Fabian y Goren, 2001). Situación distinta es la del almacén cartagenero, no ligado a un centro productor-exportador, sino consumidor. Aquí, ninguno de los contenedores ha conservado su sistema de cierre; por el contrario, incluso uno de ellos evidencia muestras de claro uso. Un ánfora tunecina (MOL15-35426-7-157-1) tiene una pequeña perforación circular que atraviesa su cuerpo. Posiblemente pueda interpretarse como un sistema de vaciado complementario al propio vertido por la boca. Se ha propuesto que el tamaño de tales perforaciones 
de evacuación se adecuaría al tipo de producto contenido en el ánfora, de tal modo que orificios de las dimensiones del documentado se relacionarían con líquidos fluidos, poco espesos (Bonifay, 2004: 467-468, fig. 264a). Estas son evidencias a tener en cuenta, pues en el contexto del papel que Carthago Spartaria desempeñó en la cadena comercial de los siglos VI-VII d. C., este almacén estaría ligado a un contexto consumidor definitivo y no de recepción y redistribución hacia otros puntos.

Sea como fuere, a pesar de las escasas dimensiones de este nuevo almacén, conviene incidir en su verdadera capacidad. De un total de 16 ánforas, 12 son de grandes dimensiones (fig. 7). En el caso concreto de las ánforas tunecinas (9 en total), su altura (algo superior al metro) y diámetro máximo $(c a .40 \mathrm{~cm})$ indican un volumen que en ocasiones puede rondar los 80-90 l (Bonifay y Bernal, 2008). Sin embargo, recurriendo a una de las metodologías de cálculo de capacidad más recientes (Molina y Mateo, 2018), nuestro hegemónico tipo Keay 61 C/Bonifay 48 contendría algo menos, posiblemente hasta ca. $48 \mathrm{l}$ y las variantes Keay 61 B o D/Bonifay 49, ca. 78,1 +/- 13,9 1, en tanto que el tipo más temprano, Keay 62/Bonifay 46 A, podría contener ca. 57.6 +/- 7,2 1. Las ánforas de posible procedencia ebusitana, de dimensiones parecidas, tendrían también una capacidad no inferior, si bien para estas no se dispone de estimaciones empíricas por su reciente individualización, así como por la fragmentariedad de sus ejemplares. En el caso de los envases orientales, a su menor tamaño corresponde, evidentemente, una menor capacidad; para el ánfora LRA 1 se estima un promedio de ca. 15,3 +/- 3.2 l (Molina y Mateo, 2018: 306, table 1), aunque no hay que perder de vista la heterogeneidad de subtipos y el progresivo atrofiamiento que experimentan algunos de ellos, con las ímplicitas reducciones de capacidad. Ilustra este problema el pecio de Yassi Ada I, donde los ejemplares pertenecientes al mismo tipo LRA 1Bl, al que también se adscribe el envase recuperado en el almacén cartagenero, van desde los $15 \mathrm{l}$ de los modelos más grandes a los 4,5 l de los más pequeños (Pieri, 2005: 75).

Lamentablemente, tampoco existen estimaciones para las ánforas tardías de posible producción local, si bien su práctica identidad dimensional con el tipo sirio-palestino ya referido permite intuir una capacidad semejante.

Con ello, el contexto documentado pudo llegar a almacenar ca. $1000 \mathrm{l}$, sea cual sea el producto contenido en estos envases: aceite, vino o, quizá simplemente, una mezcla de ambos. Se trata de un volumen que excede con mucho las necesidades de un grupo familiar, sugiriendo un consumo por parte de un colectivo más amplio. El contexto supera la capacidad de almacenaje de otros depósitos documentados en Carthago Spartaria, como los del barrio ubicado sobre el antiguo teatro augusteo. Allí, en el nivel de destrucción datado en el primer cuarto del siglo vir d. C., algunos de estos espacios contenían cerca de una decena de grandes ánforas, como ocurre en la denominada habitación n. ${ }^{\circ} 2$, que proporciona cinco ejemplares tunecinos del tipo Keay 61 y otros dos ibicencos (Ramallo et al., 1996: 172-178, fig. 12-16). No obstante, las estancias aledañas (n. 3 y 4), imbricadas en un mismo conjunto, también albergan otros contenedores, lo que aumentaría la capacidad de acopio. 

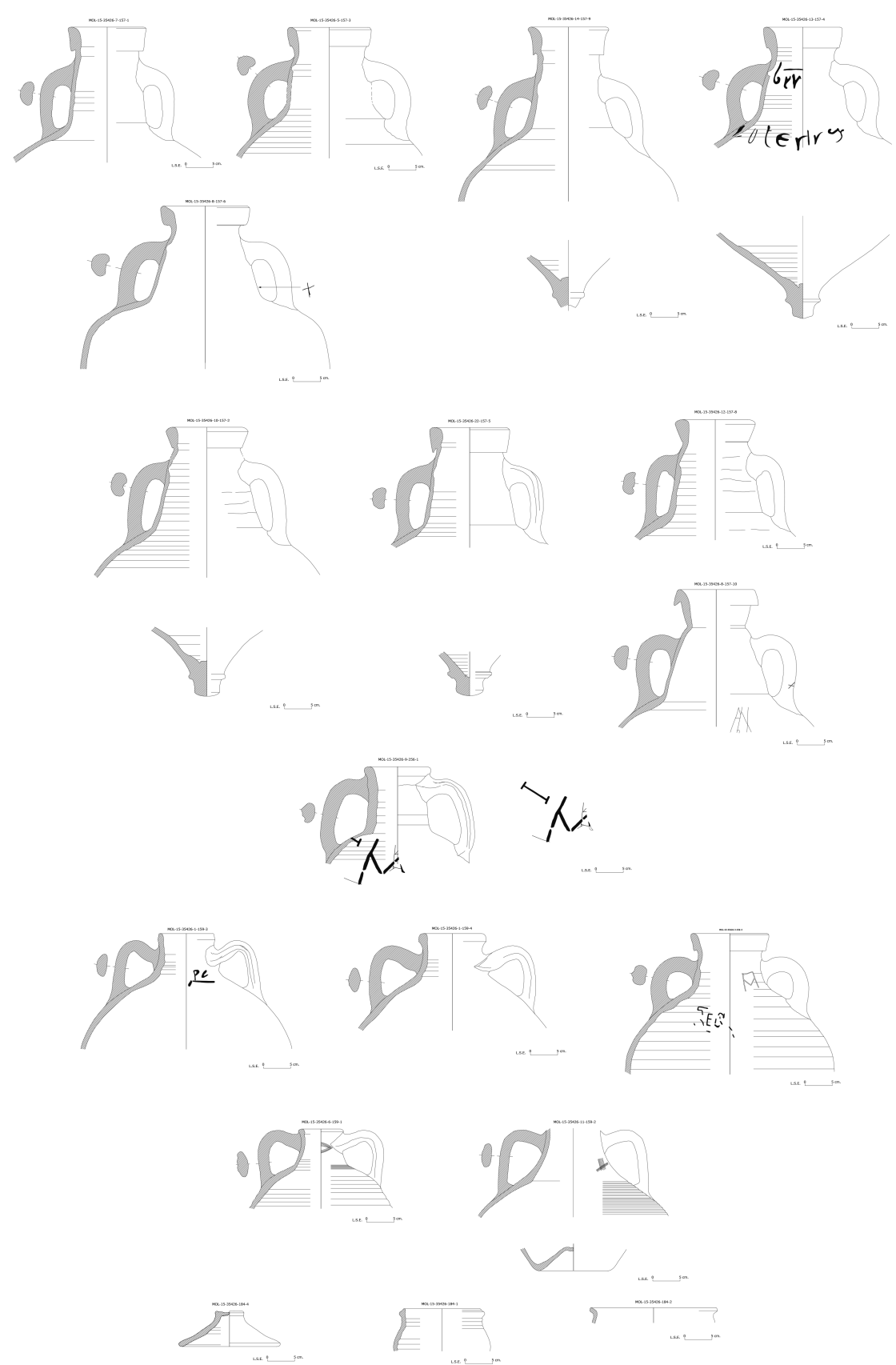

Figura 7. Depósito cerámico UE 35426 del almacén de época bizantina de la arx Hasdrubalis (dibujo: L. Suárez Escribano). 


\subsection{Características del contexto estratigráfico}

El depósito cerámico objeto de estudio (UE 35426) apareció depositado sobre el nivel de uso de la habitación n. ${ }^{\circ}$ 40. Este último (UE 35449), definido por un exiguo registro material, proporcionó un pivote anepígrafo de late roman unguentarium $(L R U)$, así como tres nummi de la ceca local bizantina. El primero pertenece a una producción que, por ahora, se constata en Carthago Spartaria exclusivamente bajo su etapa de dominio bizantino (Vizcaíno y Pérez, 2008). Referente a las evidencias numismáticas, realizadas en cobre, se caracterizan por un formato mínimo y una iconografía regular: una cruz en el anverso y una delta griega en el reverso, alusiva al valor del numerario: 4 nummi (Lechuga, 2000). Estas monedas son usuales en los contextos cartageneros de la segunda mitad del siglo vi y principios del siglo vII d. C., teniendo su posible correlato en los nummi que, presumiblemente, acuñó Malaca, la otra gran ciudad hispana bajo dominio bizantino (Mora, 2017: 188-192).

Sobre este nivel de uso (UE 35499), como indicamos, se documentó el conjunto cerámico UE 35426 (fig. 3 y 6). Todas sus piezas, incluidas las escasas de vajilla, estaban aplastadas contra el suelo, de modo que, aunque el número de individuos es menor, durante la excavación llegaron a individualizarse 26 grupos cerámicos en función de su agrupamiento espacial. A pesar de este elevado índice de fragmentación, la mayoría de ejemplares apenas ha perdido partes significativas de su cuerpo, pudiéndose realizar un adecuado remontaje y restauración. Junto al citado aplastamiento, también se advierten algunas señales de combustión parcial. Así, el ánfora MOL15-35426-5-157-3 muestra algunos fragmentos ennegrecidos por efecto de su exposición al fuego, en tanto que otra pieza (MOL15-3542612-157-8) conserva restos de hollín. Se trata de indicios que sugieren un episodio de destrucción prácticamente coetáneo al subsiguiente desplome de las cubiertas y derrumbe de los alzados de adobe, testimoniados mediante bolsadas de filitas y arcillas anaranjadas. Tras este episodio se constata el consiguiente abandono (UUEE 35421 y 35420), en el que apenas puede reseñarse material significativo; con la excepción de un pivote anepígrafo de $L R U$, algunos informes de ánforas norteafricanas o las siempre frecuentes cerámicas de cocina de producción local, se registran (como es propio de estos estratos) fragmentos dispares, muy rodados y, en su mayoría, claramente residuales, que abarcan desde cuencos de Terra Sigillata Sudgálica a cerámica de cocina africana de los siglos II y III d. C.

\subsection{Análisis del depósito cerámico}

La composición del registro cerámico no deja dudas acerca de la especialización del espacio. Aunque hay algunos restos de vajilla, son mínimos y en ocasiones, residuales, evidenciando que, a diferencia de otros lugares en donde en una misma estancia se combinan las funciones doméstica y de almacenamiento, aquí esta última es exclusiva. Dicha especialización atañe también al módulo de los contenedores, pues, salvo dos orientales y otros tantos locales, el resto (un total de 12 africanos y ebusitanos) son ánforas cilíndricas de 
grandes dimensiones. Están ausentes los pequeños spatheia tunecinos, tan abundantes en los contextos del Mediterráneo tardoantiguo y generalizados en los niveles bizantinos de Carthago Spartaria (Reynolds, 2011: 109-111, fig. 5-7, tabla 1), incluidos los de El Molinete (Vizcaíno et al., 2019). Comoquiera que sea, aunque el número de envases no es alto, limitándose a 16, la elevada capacidad de algunos — como ya se ha referido- expone la verdadera envergadura del conjunto.

\subsection{1. Ánforas africanas}

Existe una mayoría de ánforas tunecinas: 9 de un total de 16. Todas pertenecen a la categoría de ánforas cilíndricas de grandes dimensiones, sobresaliendo el tipo Keay 61/Bonifay 48/49 (fig. 8-9). Con 8 ejemplares adscritos a sus diversas variantes, acapara la práctica totalidad de la muestra. Se trata de un contenedor cuyo origen se sitúa en el Sahel tunecino, en talleres como el de Moknine y, probablemente, también Leptiminus, pauta de la que solo parecen distanciarse las variantes más tardías (Bonifay, 2004: 141; Capelli y Bonifay, 2014). Los estudios recientes, en todo caso, reivindican el protagonismo de la primera de las regiones, en el hinterland de Salakta, la antigua Sullecthum (Bonifay, 2016: 605). De hecho, la Byzacena septentrional se está revelando como una de las zonas más activas en el abastecimiento a gran escala a diversos lugares del Mediterráneo central y occidental, caso del castro bizantino de San Antonino di Perti, en Liguria, donde las importaciones parecen prolongarse hasta un momento avanzado del siglo viI d. C. (Gandolfi et al., 2010: 37-42). Dicha región parece desplazar a la Zeugitana, pujante, sin embargo, en la producción y difusión anfórica durante el siglo v d. C. Esta basculación se puede apreciar en otros lugares de la costa hispana, como Valentia (Rosselló y Ribera, 2005) o Tarraco, donde a la evidencia tipológica se une el análisis arqueométrico (Fantuzzi et al., 2015).

Lamentablemente, a pesar del creciente número de hallazgos, aún es difícil determinar el contenido de estos grandes contenedores tunecinos. Su región productora y, puntualmente, el análisis de residuos han hecho que tradicionalmente se asocien al transporte de aceite. Con todo, el resinado de algunos ejemplares y nuevos análisis de contenido abogan por mantener un abanico más amplio de productos (Bonifay, 2016).

En este almacén el tipo Keay 61 C/Bonifay 48 es el más representado, con hasta tres ejemplares (fig. 8). Este tipo se asocia al taller de Henchir ech-Chekaf, en Ksour Essaf, datándose entre finales del siglo vi y la primera mitad del vII d. C. (Bonifay, 2004: 140, fig. 16.5 y 75). De hecho, tal vinculación a este taller cercano a Mahdia ha motivado su sistematización como tipo Ech Chekaf II.1 (Nacef, 2007: 46, fig-10.3-6), muy semejante, por otro lado, a algunas variantes del coetáneo tipo Ech Chekaf II.2. Junto a las características morfológicas que apoyan la adscripción tipológica, también se constata la pasta propia de este taller de la Byzacena septentrional, de color naranja y con inclusiones calcáreas o microfósiles, de tamaño medio-grande, que en ocasiones afloran en la superficie (Bonifay, 2004: 34-35; Capelli y Bonifay, 2014: 237). Su presencia en Cartagena es destacada, en sintonía con su 

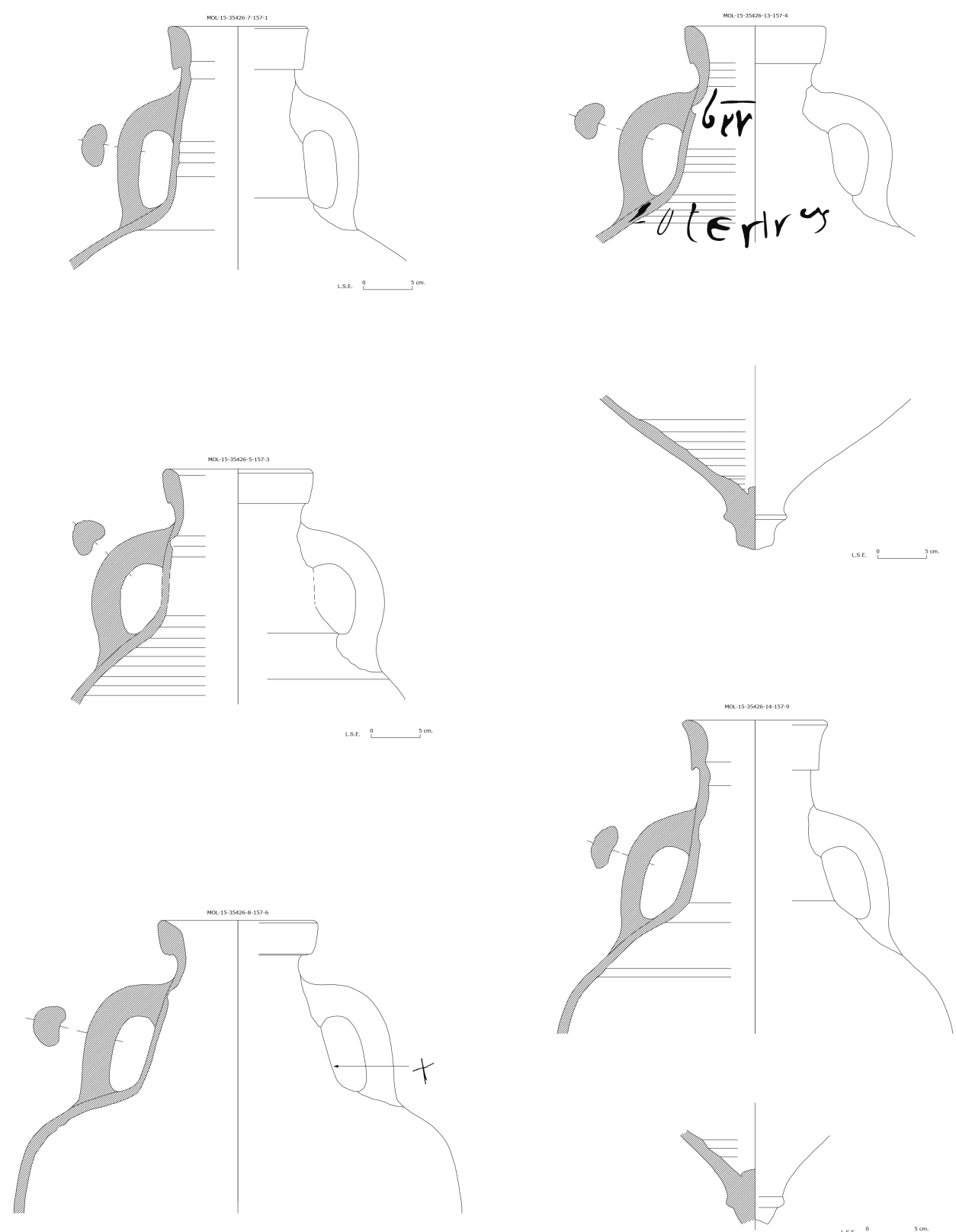

Figura 8. Ánforas tunecinas tipos Keay 61 C/Bonifay 48 y Keay 61/Bonifay 49 B documentadas en el almacén de época bizantina (dibujo: L. Suárez Escribano). 
buena difusión en el conjunto del Mediterráneo occidental y los Balcanes (Reynolds, 2011 : 111). En otros lugares hispanos, como el enclave valenciano de Punta de l'Illa de Cullera, el tipo 61 C/Bonifay 48, se registra asociado a las ánforas tunecina Keay 62 o ibicenca RE-0103 b (García y Rosselló, 1992), como también ocurre en el almacén que analizamos.

De los tres ejemplares, dos tienen sendas marcas en su cuello, consistentes en un simple grafito en forma de aspa (MOL15-35426-8-157-6) o en un titulus pictus de cierto desarrollo (MOL15-35426-13-157-4). Para el titulus, dispuesto en al menos dos renglones, es difícil proponer una lectura plausible, dado el tipo de cursiva empleada. ${ }^{2}$ Ciertos caracteres inducen a pensar que se usó el latín o, como también es frecuente en este momento, el griego con caracteres latinos. En este sentido, cabe notar en la línea inferior el empleo de dos letras de grafía latina como la «t» o la «r», sin que ello sea determinante. A modo de hipótesis, proponemos la lectura "Sotericus», cognomen que quizás aluda al propietario o comerciante. De ser acertada tal hipótesis, se trata de un nombre que, con cierta tradición, continuó gozando de vigencia en época protobizantina, incluso entre la élite, como muestran los casos del magister militum per Thracias, entre los años 491 y 518 d. C., y del cónsul de 525 d. C., Flavius Theodorus Philoxenus Sotericus (Jones et al., 1992: 879).

A la hegemónica ánfora Keay 61 C/Bonifay 48 ya analizada, sigue en importancia cuantitativa el tipo Keay 61/Bonifay 49 B, representado en el depósito con un par de ejemplares (MOL15-35426-7-157-1 y MOL15-35426-14-157-9) (fig. 8). Se trata de un tipo documentado abundantemente en Cartagena. Así, destaca su registro en el nivel 10.2 del barrio levantado sobre el teatro, correspondiente a su destrucción violenta datada en el primer cuarto del siglo vII d. C. (Ramallo et al., 1996: fig. 19, n. ${ }^{\circ} 253$ ). Esta variante, a diferencia de los ejemplares más tempranos del tipo Keay 61, no parece ser una evolución directa del tipo Keay 62/Bonifay 46, fechándose entre finales del siglo vi y la primera mitad del vir d. C. (Bonifay, 2004: 141). En nuestro caso, una de las piezas (MOL15-35426-7157-1), de pasta y superficie amarillenta, ha perdido gran parte de su pátina y muestra la pequeña perforación antes referida, presumiblemente asociada al vertido del líquido.

Al mismo espectro temporal, finales del siglo vi y primera mitad del vII d. C., pertenece otro envase (MOL15-35426-22-157-5) (fig. 9), encuadrable en el tipo Keay 61/Bonifay 49 D, una de las variantes más tempranas de esta serie de grandes contenedores. Quizás esta precocidad, asociada a su inmediata derivación del tipo Keay 62/Bonifay 46, sea la causante de la similitud morfológica de sus pivotes, no mostrando el apéndice interno en el eje axial del fondo que caracteriza las demás variantes del tipo Keay 61/Bonifay 49 (Bonifay, 2004: 140-141, fig. 75.1). El envase se documenta asiduamente en la costa hispana y su inmediato hinterland, en enclaves rurales como L'Horta Vella (Bétera, Valencia), donde aparece en su fase III, fechada entre finales del siglo vi y mediados del vir d. C. (Jiménez et al., 2005, 312-314, lám. 6).

2. Este tipo de inscripciones sobre soporte cerámico, grafitos y tituli picti, está siendo estudiado por la Dra. M. P. de Hoz García y Bellido (Facultad de Filología Clásica de la Universidad Complutense), a quien se deben estas observaciones preliminares. 

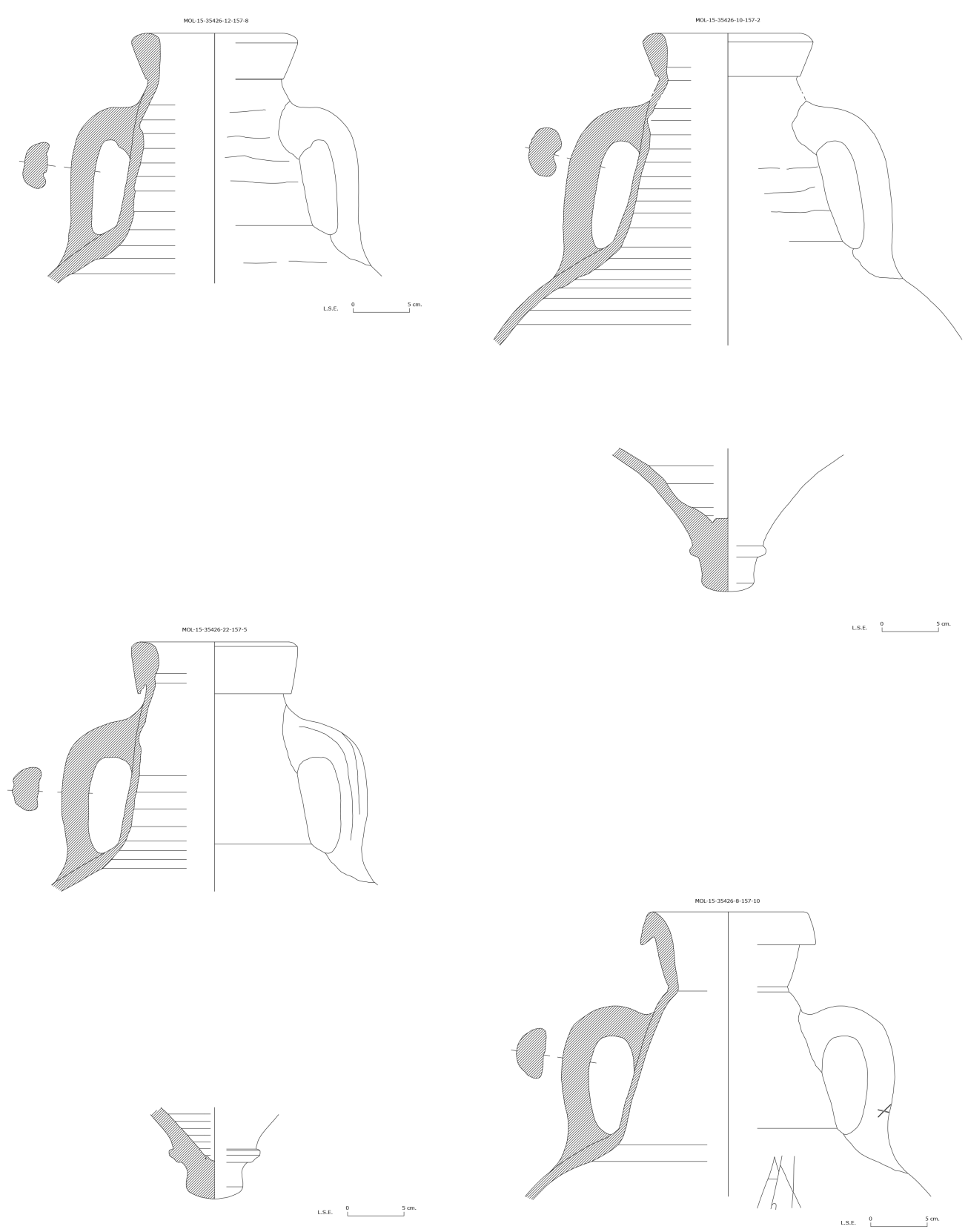

Figura 9. Ánforas tunecinas tipos Keay 61/Bonifay 49 D; posible variante tardía del tipo Keay 61/Bonifay 49 y tipo Keay 62/Bonifay 46 A (dibujo: L. Suárez Escribano). 
Más incierta es la adscripción de otras dos piezas (MOL15-35426-12-157-8 y MOL1535426-10-157-2) (fig. 9), cuyo borde guarda similitud con algunas de las variantes más tardías del tipo Keay 61/Bonifay 49, manufacturadas no ya en la Byzacena, sino en talleres de la Zeugitania, como el de Sidi Zahruni (Beni Khiar), en las cercanías de Neapolis (Bonifay, 2004: 37-39, fig.18.24). La cronología de esta variante, documentada en Marsella, se ha establecido a partir de mediados del siglo vII d. C. (Bonifay, 2004: 141, fig. 75.10). Uno de los ejemplares de El Molinete conservaba restos de hollín.

La adscripción tipológica plantea dudas, así como la propuesta de datación defendida en los estudios más recientes (Bonifay, 2004: 141). Dicha cronología, sin que ello sea per se un argumento excluyente, no parece guardar relación con las fechas a las que apunta el resto de envases que componen este contexto. De hecho, insiste en ello, en su cronología previa el hecho de aquí aparezca también asociado a contenedores algo más tempranos, como el tipo Keay 62/Bonifay 46. A su variante Bonifay 46 A, datada en la primera mitad del siglo vi d. C., pertenece un ejemplar (MOL15-35426-8-157-10) con sendos grafitos en el galbo superior y el asa (fig. 9). El primero es un monograma latino en letra capital, en que se pueden identificar las letras A y N. El segundo es apenas una marca en forma de aspa situada en el arranque del asa. Este envase, considerado tradicionalmente como el ánfora vándala por excelencia, fue manufacturado en diversos talleres tunecinos. Para esta variante más temprana, las figlinae se sitúan preferentemente en la región de Byzacena, aunque se ha documentado una producción minoritaria en Zeugitania (Bonifay, 2004: 137-140). De hecho, el ejemplar cartagenero es muy similar a otros salidos del taller de Henchir ech-Chekaf (Bonifay, 2004: fig. 74.7), que ocupa una posición básica en la producción de las aquí mayoritarias Keay 61. Algunos análisis químicos de residuos sugieren la posibilidad de que ejemplares de este tipo Keay 62 / Bonifay 46, al menos de alguna de sus variantes (Keay 62Q/Bonifay 45), contuviesen aceite de ricino, utilizado entre otros usos para la iluminación (Pecci et al., 2010).

\subsection{2. Ánforas de probable procedencia ibicenca}

Junto a este considerable lote de ánforas tunecinas, el almacén contaba también con una discreta representación de ánforas de otras procedencias (fig. 10). Destacan primero las ánforas consideradas ibicencas. Se trata de una categoría de piezas recientemente individualizada, pues aunque su presencia ya estaba documentada en los niveles de los siglos VI-VII d. C. de la costa levantina, como los de Punta de l'Illa de Cullera o el barrio bizantino del teatro de Cartagena, su identificación suscitaba interrogantes. Ciertas similitudes morfológicas motivaron incluso su adscripción al tipo Keay 32, aunque ni el paralelo era del todo exacto, ni la horquilla cronológica sugerida por S. Keay (1984) consideraba una circulación tan tardía. Nuevos trabajos han arrojado luz sobre esta producción. Destacando la deuda con los prototipos norteafricanos en boga, el análisis de las pastas y una documentación cada vez más numerosa apuntan un origen baleárico y, más en concreto, ibicenco (Pecci et al., 2019). De hecho, destaca su registro yacimientos de Ibiza como Ses Païsses de 
El almacén anfórico del barrio de El Molinete (Cartagena)

J. Vizcaíno; J. M. NOGUera; M. J. MAdrid
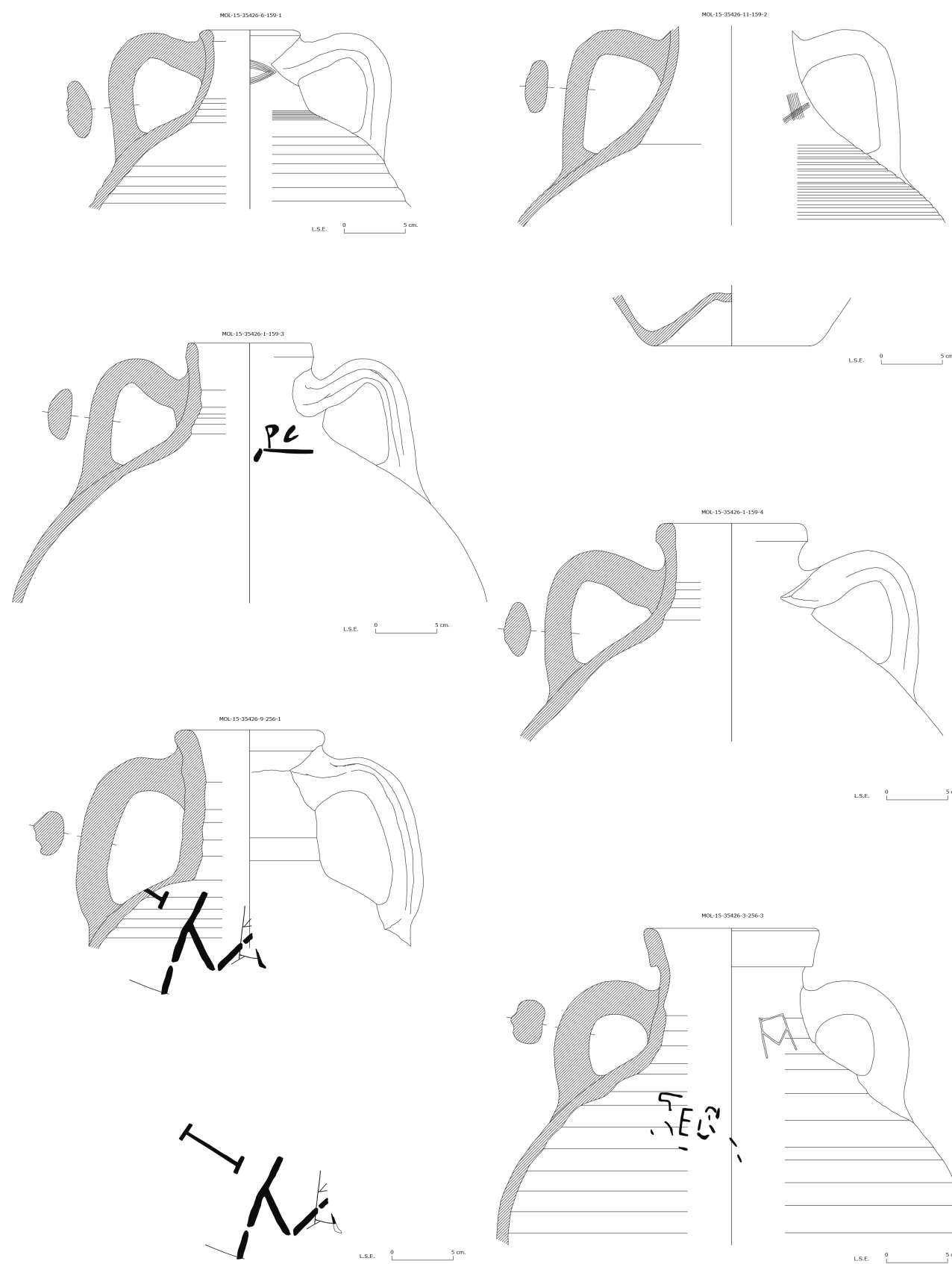

L.S.E.

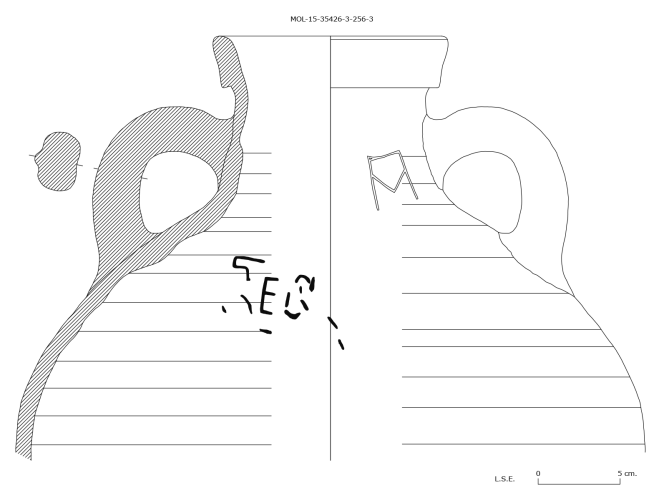

Figura 10. Ánforas de producción ibicenca, oriental y posible manufactura local/regional, documentadas en el almacén de época bizantina (dibujo: L. Suárez Escribano).

PYRENAE, vol. 51 núm. 2 (2020) ISSN: 0079-8215 EISSN: 2339-9171 (p. 99-129)

117 
Cala d'Hort y Es Clot, entre otros, en niveles de finales del siglo vi y el vII d. C. (Ramon, 2008: 574, fig. 7). A su amplia presencia insular (Riera, 2017: 476-479), hay que unir una distribución capilar por la costa hispanomediterránea, que comprende al menos desde la antigua Iluro a Malaca, teniendo un jalón importante en los entornos de Valentia (Ribera y Rosselló, 2012) y Carthago Spartaria (Reynolds, 2010: fig. 23b).

En el contexto objeto de estudio, dos piezas (MOL15-35426-1-159-4 y MOL15-3542619-159-3) (fig. 10) pertenecen claramente al tipo RE-0103 b, definido por su característico cuello corto, así como por asas de perfil oblicuo acodado y borde apenas engrosado, con labio redondeado o ligeramente entrante (Ramon, 2008: fig. 7.2-3). Uno de los envases (MOL15-35426-19-159-3) tiene un titulus pictus en el hombro, característica muy habitual en estos contenedores. A pesar de estar la inscripción prácticamente perdida, sugerimos interpretarla como una posible cruz monogramática. Su asta vertical se remata en la característica rho, en tanto que a su derecha se aprecia otro carácter, quizá — con todas las cautelas - una posible sigma lunar.

Otro ejemplar de posible producción ibicenca (MOL15-35426-3-256-3) también cuenta con inscripciones (fig. 10); el engrosamiento rectangular de su borde, en sintonía con las ánforas tunecinas que parecen servir de referentes, sugiere su adscripción a la otra variante del tipo ebusitano RE-0103 a (Ramon, 2008: fig. 7.1). Superficie y pasta son de color beige claro, destacando diferentes inclusiones como unas partículas blanquecinas de tamaño pequeño. A diferencia de las anteriores, tiene asas de sección oval simple cuya nervadura central le confiere cierto perfil trilobulado. Respecto al monograma en bloque que muestra

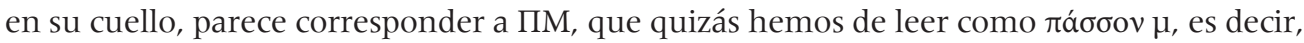
40 kotyles, o lo que es lo mismo 1 modio de vino resinado. ${ }^{3}$ Si tal lectura preliminar fuese cierta, estaría en sintonía con la naturaleza que se defiende para los contenedores ibicencos. De hecho, los análisis de residuos orgánicos practicados en otros yacimientos indican la presencia de ácido tartárico y otros componentes que se pueden considerar indicadores del almacenamiento de vino, evidencia que concuerda con el resinado de muchas de las piezas (Pecci et al., 2019).

En el caso de la arx Hasdrubalis, estos envases ebusitanos son bastante comunes en los niveles de época bizantina, destacando entre otros, por su estado de conservación y epigrafía asociada, uno hallado en una atarjea relacionada con la refacción de la muralla de la cima del cerro (Vizcaíno et al., e.p.).

\subsection{3. Ánforas orientales}

Frente al fuerte componente africano del almacén cartagenero, las ánforas orientales tienen una presencia exigua, casi anecdótica. Se limita a 2 ejemplares del total de 16. Ambos pertenecen al tan extendido tipo Late Roman Amphora 1. En uno de los casos (MOL15- 
35426-9-256-1) (fig. 10), su estado de conservación es bastante bueno; en otro, solo contamos con fragmentos informes que impiden una discriminación tipológica fiable. Respecto al primero, sus características morfológicas, especialmente el diámetro amplio de su boca y cuello, el engrosamiento del borde y la posición de las asas, sugieren su inclusión en la variante LRA 1B1, cuya circulación en Occidente se ha establecido entre principios del siglo vi y mediados del vir d. C. (Pieri, 2005: 75-76, láms. 15-18). En el hombro tiene un titulus pictus hecho con pintura ocre, que no se conserva completo dada la fragmentariedad del recipiente. La lectura del texto es harto compleja. Los análisis paleográficos han puesto de manifiesto que la ubicación en una parte concreta del envase marca el sentido de estos dipinti (Fournet, 2012). En concreto, los situados entre el cuello y los hombros, a la altura del arranque de las asas, suelen corresponder a datos metrológicos, expresados generalmente en la medida de capacidad más difundida, el sextarius.

Los análisis petrográficos o el abundante registro de ejemplares evidencian la producción de la LRA 1 en diversas zonas orientales, como la costa suroeste de Chipre o incluso Éfeso. Uno de los principales focos productivos parece radicar en la costa de la antigua Cilicia, en concreto en la franja entre Seleucia Pieria y Elaiussa Sebaste (Pieri, 2005: 80). En concreto, para nuestra variante LRA 1B, las pastas del tipo P3 se adscribirían a la primera ciudad, en tanto que las del tipo P5 a la no lejana Arsuz, y la P4, sin embargo, a Amathonte de Chipre (Pieri, 2005: 81). Abundando en la ubicación de tales focos productivos, se considera que este envase puede corresponder al que los textos denominan Cilicises (Isid. Hisp. Etym. XX, VI, 6). Este, al parecer, distribuyó el célebre vino de esta región, ya referido en la Expositio totius mundi et gentium (XXXIX) y más tarde mencionado por autores como Pablo de Egina (XXII), quien lo prescribe por sus virtudes médicas (Pieri, 2005: 80-85). De su amplia difusión hasta época avanzada, incluso fuera de los circuitos más habituales, da cuenta su documentación en puertos atlánticos como el de Vigo, donde el tipo LRA 1B llega a representar el $76 \%$ de las ánforas orientales en los contextos de finales del siglo VI e inicios del vir d. C. (Fernández, 2016: 122-123).

\subsection{4. Ánforas de procedencia indeterminada}

Cierran el repertorio anfórico sendos ejemplares de posible manufactura local/regional (fig. 10). Uno de ellos (MOL15-35426-6-159-1) ha conservado la mitad superior de su cuerpo, permitiendo apreciar los caracteres de estos envases. Morfológicamente, muestran relación con el referido tipo oriental LRA 1, del cual pudieron ser una imitación. Cuentan con cuerpo acanalado de tendencia ovoide, asas de sección oval, cuello troncocónico de escaso desarrollo y borde exvasado y engrosado. Es frecuente que estos envases estén decorados a peine, reproduciendo franjas horizontales o, como en el caso que nos ocupa, trenzados. En ocasiones, sin embargo, se trata solo de pequeños motivos en aspa, como muestra el ejemplar MOL15-35426-11-159-2, que, si bien conservado de manera más precaria, permite restituir su fondo, que es umbilicado, el propio de estos envases. 
Aunque recientemente se ha señalado la semejanza entre este tipo «local» y otro hallado en las Baleares, con ejemplos como el de la basílica menorquina de Es Cap des Port (Reynolds, 2015: 189, fig. 14 d), no nos consta el registro de esta producción fuera de Cartagena. Esta circunstancia, unida a los caracteres de su pasta, sugiere tenerlo como una manufactura del entorno de Cartagena. De hecho, en sus pastas se advierten, junto a pequeñas partículas micáceas, los esquistos plateados y violáceos tan característicos del sureste hispano. Las pastas son bastante homogéneas, depuradas y con una coloración mayoritariamente anaranjada-rojiza y, en menor medida, beige-amarillenta. Con anterioridad se había defendido su producción a partir del siglo vir d. C. (Ramallo et al., 1997: 210, fig. 10, 1), pero los nuevos hallazgos prueban su presencia ya en niveles de la centuria anterior. Así, tanto las pastas como ciertos rasgos morfológicos parecen emparentar estos pequeños contenedores con el denominado tipo El Mojón III, salido de un alfar de la costa meridional de Cartagena, activo hasta el primer cuarto o, quizá, mediados del siglo vi d. C. (Berrocal, 2012: 256-272, fig. 7). En ausencia de análisis de residuos y otros estudios arqueométricos más precisos, el contenido de estas ánforas es aún desconocido. No obstante, el hecho de que tomen como referente tipológico un contenedor vinario, el LRA 1, o que las imitaciones que de él se registran en otros ámbitos productivos como el norteafricano se asocien también al transporte de vino (Bonifay, 2016: fig. 2), hacen que sea sugerente considerar un mismo fin.

\subsubsection{Otros materiales cerámicos}

Junto a las ánforas, componente casi exclusivo del almacén, también se constataron otros recipientes. Entre ellos, destaca la cerámica de cocina local, tradicionalmente denominada «tosca» (Láiz y Ruiz, 1990; Murcia y Guillermo, 2003), aquí representada por dos ollas y una tapadera (fig. 7). Los criterios de atribución local para esta producción residen, aparte de su cuantiosa presencia en los niveles tardíos de la ciudad, en análisis químicos y petro-

gráficos. Estos demuestran la presencia de filitas y cuarcitas, así como pequeños fragmentos de rocas volcánicas y cristales de feldespatos y piroxenos que los estudios mineralógicos vinculan con fenómenos de vulcanismo calcoalcalino constatados en la comarca sudoriental del Campo de Cartagena, en particular en el área del Mar Menor (Milá y Arana, 2007). Por otro lado, analogías formales y análisis petrográficos también han permitido documentar su presencia en las Baleares (Cau, 1995 y 1999: 203-206), con todo lo que ello implica de comercialización de esta producción que poco a poco se revela "no tan menor».

Uno de estos recipientes se ha podido reconstruir casi de manera íntegra (MOL1535426-184-1). Puede adscribirse a uno de los tipos más populares, el CT 1.4, que comprende las ollas de borde moldurado externo y perfil interior redondeado (Láiz y Ruiz, 1990: 272-275). También se han recuperado varios fragmentos de una tapadera (MOL1535426-184-4), cuyo labio redondeado se incluye en el tipo CT 14. Distinto es el caso de dos recipientes, cuya exigua representación (limitada a un solo fragmento de escasas dimen- 
siones) y su amplia cronología sugieren su posible residualidad. Se trata de una olla CT 2.1 (MOL15-35426-184-2) y de una cazuela de posible procedencia suritálica (MOL15-35426184-5), algo habituales en los contextos locales del siglo v y la primera mitad del vi d. C.

\subsubsection{Consideraciones generales sobre el depósito cerámico}

Referente a la cronología del conjunto (fig. 7), la mayoría de ánforas se encuadra en tipos claramente fechables a partir del último cuarto del siglo vi d. C., sino antes — como sucede con los tipos Keay 62 o LRAl一, si bien otros dos envases guardan similitud con las variantes tardías del tipo Keay 61/Bonifay 49, que se han datado a partir de mediados del siglo vII d. C. (Bonifay, 2004: 141, fig. 75.10). Desconocemos hasta qué punto esta última adscripción es fiable y si, con ello, hemos de seguir dicha horquilla cronológica y retrasar la cronología del depósito hasta esa fecha. Sin embargo, creemos que el contexto apunta casi de manera exclusiva una data previa, que no parece posterior al primer cuarto del siglo VII d. C. Aunque el argumento ex silentio no es determinante, tampoco parece casual que en el almacén haya un repertorio tan amplio de contenedores tunecinos y, sin embargo, falte la variante que caracteriza los momentos más tardíos, caso del tipo Keay 61/Bonifay 49 A, datada a partir de mediados del siglo vil d. C. (Bonifay, 2004: 139, fig. 75.4). De hecho, esta última no falta en otros contextos del sureste a lo largo de la centuria, como ocurre en El Tolmo de Minateda (Hellín, Albacete), donde la encontramos ya en la fase ligada al uso de las construcciones visigodas (fase 3.2) y también en otros contextos más tardíos, en clara residualidad (Amorós, 2018: 254-255, fig. 221 g).

Insistiendo en la datación que manejamos, creemos que el registro cerámico documentado parece distinto en cantidad y diversidad, a la de otros contextos datados en un momento avanzado del siglo viI d. C. Resulta así sumamente esclarecedor contrastar la composición del depósito cartagenero con la de almacenes de otras ciudades costeras, como Tarragona. Aquí, en contextos de almacenaje portuarios de la segunda mitad del siglo vir d. C., el material anfórico no solo da cabida a una mayor, aunque discreta, presencia de envases orientales, sino que también los mismos contenedores norteafricanos son sustancialmente diversos (Rodríguez y Macías, 2016). Aunque se mantiene el protagonismo del tipo Keay 61, lo hace bajo la abultada preponderancia de una de las variantes más avanzadas, la 61 A y, en menor medida, de los tipos Keay 8 A y Keay 61/8 A, reservando un lugar casi residual a la variante más representada en Cartagena, la Keay $61 \mathrm{C}$.

\section{Conclusiones}

Aunque la cronología del nuevo contexto de El Molinete se presta a debate, argumentos estratigráficos y el análisis tipológico de los envases nos llevan a defender su datación en 
el primer cuarto del siglo vII d. C., entroncando con los denominados contextos de «destrucción" documentados en el barrio bizantino sobre el teatro de Cartagena (Ramallo et al., 1997; Reynolds, 2011). En este sentido, la documentación arqueológica parece acorde a las fuentes textuales y, particularmente, al testimonio isidoriano que alude a la destrucción de la ciudad ca. 625 d. C. (Isid. Hisp., Etym. XV, I, 67-68), noticia después de la cual no volvemos a encontrar referencias escritas fiables sobre Carthago Spartaria. No en vano cabe recordar que tal silencio documental se prolonga hasta el siglo $\mathrm{x}$, momento en que tal nombre queda "fosilizado" en aquel que darán las fuentes árabes a un puerto ya recuperado, Qartayanna al-Halfa (Pocklington, 1986: 321-324).

En nuestro caso, a la cronología aportada por el depósito cerámico del almacén, hay que añadir el registro en el nivel arqueológico inmediatamente inferior de tres nummi pertenecientes a la ceca local abierta en la ciudad en época bizantina. Se trata de una evidencia singular, pues a su presencia constante en los niveles de este período se suma la marca de valor empleada, una delta griega, testimonio del ambiente helenizante que impulsa la implantación bizantina en el sureste peninsular. Propia de la segunda mitad del siglo VI y principios del vII d. C., dicha ceca parece formar parte de un fenómeno más amplio de acuñaciones locales constatadas en otras urbes hispanas bajo dominio imperial, como se ha sugerido también para el caso de Malaca (Mora, 2017: 188-192). En el nuevo almacén, refuerza estas impresiones su presencia junto a uno de los característicos $L R U$, hasta cierto punto uno de los "fósiles directores» de la etapa (Vizcaíno y Pérez, 2008).

Creemos que la composición de los contextos de Carthago Spartaria solo encuentra una explicación cierta durante su fase de dominio bizantino, liquidada con el envío de las tropas del rey visigodo Suintila (Vallejo, 2012: 340-344). Aunque hallazgos cerámicos como los de Recópolis, entre otras ciudades de la Hispania visigoda, prueban que las mercancías importadas circulan a un lado y otro de la debatida frontera grecogótica (Gutiérrez, 1998; Bonifay y Bernal, 2008; Bernal y Bonifay, 2011), depósitos como el del almacén descrito solo parecen explicarse en función de unas coordenadas políticas concretas. Posiblemente, la clave del "problema» estribe no tanto en presencias o ausencias de determinados ítems, ya sean cerámicos o de cualquier otra naturaleza, como en la variedad e intensidad del registro. En línea con lo reflejado en trabajos previos (Ramallo et al., 1996; 1997), la importación tunecina en Cartagena es masiva, acaparando buena parte de los depósitos, al parecer incluso más que en Málaga, el otro gran puerto hispano bajo dominio de los milites romani (Navarro et al., 2017). No extraña así que la ciudad surestina esté inundada de "spatheia» o que la diversidad y cantidad de su repertorio vascular en Terra Sigillata Africana D apenas encuentre parangón en otras ciudades hispanas (Vizcaíno et al., 2019). Igualmente, hay que destacar el hallazgo de formas singulares apenas registradas fuera del norte de África (Vizcaíno et al., 2019), mostrando una vez más que la «bizantinización», aun contemplando sólidos vínculos con Oriente, se vivió en ella, sobre todo, como una auténtica «africanización», reforzando los ancestrales lazos entre ambas orillas (Vizcaíno, 2013).

Abundando en ello, aunque el carácter litoral de Carthago Spartaria facilitó sin duda sus vínculos comerciales con las grandes regiones productoras del Mare Nostrum —al igual 
que ocurrió también con Tarraco-, creemos que no solo es la cercanía al norte de África la que explica la abultada diferencia en el volumen de importaciones, sobre todo tunecinas, entre la ciudad del sureste y el resto de la franja hispanomediterránea (Reynolds, 2015: 187-189). Este nuevo almacén, en unión con otros contextos cerámicos del barrio bizantino de El Molinete y, sin duda, del levantado sobre el teatro, demuestran que la ciudad se benefició durante la segunda mitad del siglo vi y principios del vir d. C. de un abastecimiento de mercancías que, aparentemente, superó las necesidades de consumo de su mermada demografía. En nuestra opinión, la explicación a este hecho debe buscarse no solo en los naturales estímulos comerciales, sino especialmente en el mantenimiento de los contingentes militares desplegados en el marco de la conquista bizantina de parte del sur de Hispania, proceso en el que Carthago Spartaria se erigió como uno de los puntos direccionales preeminentes, reforzando su secular carácter de plaza fuerte. No en vano se ha destacado la similitud de sus pautas de abastecimiento con las de otros enclaves con fuerte impronta militar, caso del castro bizantino de San Antonino de Perti, en la Liguria, o Koper, en el norte del Adriático (Reynolds, 2011, 115). En la misma dirección, también en los niveles bizantinos de la arx Hasdrubalis se registran envases que algunas propuestas han ligado explícitamente a la manutención de castros y fortalezas, caso del Samos cistern type (Arthur, 1990). A este respecto, cabe recordar que fuentes diversas, como el POxy XVI, 2046, informan que hacia el año 563 d. C. la ración militar diaria incluía 3 libras de pan, otra de carne, 1 xestes de vino y la décima parte de un xestes de aceite (Morrisson y Cheinet, 2002: 870, tabla 20), todo lo que obligaría a articular los preceptivos mecanismos de avituallamiento.

Desgraciadamente, aún es frágil la documentación sobre esta suerte de mutada annona militaris en las posesiones reconquistadas por Justiniano en Occidente. De ella, apenas se vislumbran las iniciativas desplegadas en el área danubiana, con el abastecimiento implantado en el año 536 d. C. en el marco de la quaestura iustiniana exercitus (Rizzo, 2015: 299-302). No obstante, parece que África o Italia se beneficiaron de soluciones similares, al menos ocasionalmente (Murialdo, 2001: 302-303), complementando la natural coemptio (Ravegnani, 2004, 124; 2007: 133-137). La franja costera hispana bajo poder de las tropas bizantinas, focalizada en una serie de núcleos urbanos casi siempre portuarios, más allá de los cuales el dominio del territorium se muestra muy tenue (Ripoll, 1998), también pudo estar abocada a este suministro marítimo, cualquiera que fuera su sistematicidad o regularidad (Vizcaíno, 2009: 289-322).

En Cartagena, los diferentes hallazgos de armamento asociados a estos contextos, como sucede en especial con una coraza de tipo laminar o puntas de flecha de tipo ávaro (Vizcaíno, 2008), sugieren no desdeñar — ni tampoco magnificar - el peso del factor militar en la realidad material de la ocupación bizantina. El abastecimiento de la guarnición, independientemente de otras motivaciones economicocomerciales, pudo ser, por tanto, un factor de peso en la conformación de los depósitos cerámicos de Cartagena durante la segunda mitad del siglo vi y el primer cuarto del siglo viI.

Dicho esto, tampoco parece que la destrucción de la que se hace eco Isidoro de Sevilla fuese literalmente a fundamentis, haciendo desaparecer por completo una ciudad histórica y 
todos sus moradores. No cabe duda de que en los escritos del arzobispo hispalense hay una fuerte carga retórica que eleva la expulsión de los bizantinos y la consiguiente conquista de Carthago Spartaria casi a una desolación de tintes bíblicos: in desolationem redacta est, según sus propias palabras (Isid. Hisp., Etym. XV, I, 67-68). Sin embargo, por el momento, los hallazgos arqueológicos más allá de esas fechas son prácticamente inexistentes. Ocurre así con la cerámica, pero también — conviene tenerlo en cuenta- con otra serie de materiales, ya vítreos (Sánchez de Prado, 2018: 20-34) ya metálicos (Vizcaíno, 2017). En el caso de la documentación epigráfica, la única inscripción que ofrece una data concreta, la del patricio Comenciolus, se fecha en 589-590; el resto de epígrafes, tanto latinos como griegos, tampoco avala una cronología más tardía (Abascal y Ramallo, 1997: n. ${ }^{\circ}$ 208-210; De Hoz, 2014: 303-313). Otro tanto ocurre con la evidencia numismática. Entre el escaso numerario oficial registrado, la emisiones monetales más tardías son sendas piezas del entorno del barrio del teatro: un follis de Justino II acuñado en la ceca de Nicomedia ca. 573-574, asociado a las formas Hayes 101, 104/105 y 107; y un decanummium quizás atribuible a Mauricio (Lechuga, 2000: 341). En último término, es precisamente aquí, en dicho barrio de época bizantina, donde tras el episodio destructivo referido se abre lo que, por ahora, no puede ser interpretado más que como un "paréntesis ocupacional». A pesar de ser el único espacio de la topografía cartagenera ocupado en todos sus períodos históricos, se registra una suerte de "vacío" que se extiende hasta la segunda mitad del siglo Ix, momento en el que se documenta un pequeño asentamiento doméstico (Guillermo, 2014: 9-39).

En este sentido, los proyectos arqueológicos actualmente en curso, como el del Parque Arqueológico del Molinete, pueden y deben mostrar la perduración de la ciudad sobre la que callan los textos y, en consecuencia, esos horizontes materiales visigodos aún esquivos. Con todo, su naturaleza, composición, diversidad de tipos y frecuencias difícilmente podrán ser idénticos a los precedentes que aquí se analizan.

\section{Bibliografía}

ABASCAL, J. M. y RAMALLO, S. F., 1997, La ciudad de Carthago Nova: la documentación epigráfica, Murcia.

AMORÓS, V., 2018, El Tolmo de Minateda en la Alta Edad Media. Cerámica y contexto, Universitat d'Alacant, Alicante.

ARTHUR, P., 1990, Anfore dall'Alto Adriatico e il problema del Samos cistern type, Aquileia Nostra LXI, 281-296.
AUGENTI, A. y CIRELLI, E., 2010, Classe: un osservatorio privilegiato per il comercio della tarda antichità, en S. MENCHELLI, S. SANTORO, M. PASQUINUCCI y G. GUIDUCCI (ed.), LRCW3. Late Roman Coarse Wares, Cooking Wares and Amphorae in the Mediterranean Archaeology and archaeometry. Comparison between western and eastern Mediterranean, BAR Int. Ser. 2185 (II), Oxford, 605-615. 
BERNAL, D. y BONIFAY, M., 2011, Importaciones y consumo alimenticio en las ciudades tardorromanas del mediterráneo nor-occidental (ss. VI-VIII d.C.): la aportación de las ánforas, en A. GARCÍA (coord.), Espacios urbanos en el Occidente mediterráneo (s. VI-VIII), Toletum Visigodo, Toledo, 91-114.

BERROCAL, M. C. 2012, Producciones anfóricas en la costa meridional de Carthago Spartaria, en D. BERNAL y A. RIBERA (eds.), Cerámicas hispanorromanas II. Producciones regionales, Cádiz, 255-277.

BONIFAY, M., 2004, Études sur la céramique romaine tardive d'Afrique, BAR Int. Ser. 1301, Oxford.

BONIFAY, M., 2016, Amphores de l'Afrique romaine: nouvelles avancées sur la production, la typochronologie et le contenu, en R. JÁRREGA y P. BERNI (eds.), Amphora ex Hispania: paisajes de producción y consumo, III Congreso Internacional de la Sociedad de Estudios de la Cerámica Antigua (SECAH), Ex Officina Hispana (Tarragona, 10-13 de diciembre de 2014), Monografías Ex Officina Hispana III, Tarragona, 595-611.

BONIFAY, M., y BERNAL, D., 2008, Recópolis, paradigma de las importaciones africanas en el Visigothorum Regnum. Un primer balance, Recópolis y la ciudad en la época visigoda, Zona Arqueológica 9, 98-115.

CAPELLI, C. y BONIFAY, M., 2014, Archéométrie et archéologie des céramiques africaines : une aproche pluridisciplinaire, 2. Nouvelles données sur la ceramique culinaire et les amphores, en N. POULOU-PAPADIMITRIOU, E. NODAROU y V. KILIKOGLOU (eds.), LRCW 4 Late Roman Coarse Wares, Cooking Wares and Amphorae in the Mediterranean: Archaeology and Archaeometry. The Mediterranean: a market without frontiers, BAR Int. Ser. 2616 (I), Oxford, vol. I, 235-253.

CAU, M. A., 1995, Cerámicas tardorromanas de cocina con inclusiones de rocas metamórficas halladas en las islas Baleares: ¿posibles producciones de la zona de Cartagena?, Actes $d u$ Colloque de Périgeux, sup. a la Revue d'Archéometrie, 101-106.
CAU, M. A., 1999, Importaciones de céramica tardorromanas de cocina en las Illes Balears: el caso de Can Sora (Eivissa), en J. CAPEL (ed.), Arqueometría y arqueología. Monográfica Arte y Arqueología, Universidad de Granada, Granada, 197-219.

DE HOZ, M. P., 2014, Inscripciones griegas de España y Portugal (IGEP), Real Aacademia de la Historia, Madrid.

FANTUZZI, L., CAU, M. A. y MACIAS, J. M., 2015, Amphorae from the Late Antique city of Tarraco-Tarracona (Catalonia, Spain)": archaeometric characterization, Periodico di Mineralogia, Special Issue 84, 1, 169-212. FERNÁNDEZ, A., 2016, Ánforas orientais tardoantigas (Late Roman Amphorae), en A. FERNÁNDEZ y P. BARCIELA (eds.), Emporium. Mil anos de comercio en Vigo, Vigo, 122-123.

FOURNET, J. L., 2012, La "dipintologie" grecque: une nouvelle discipline auxiliaire de la papyrologie?, en P. SCHUBERT (ed.), Actes du $26^{e}$ Congrès international de papyrologie (Genève, 16-21 août 2010), Recherches et Rencontres, 30, Publications de la Faculté des Lettres de l'Université de Genève, Ginebra, 249-258.

GANDOLFI, D., MURIALDO, G., CAPELLI, C. Y BONIFAY, M., 2010, Anfore africane di tardo V-VII secolo in Liguria (Italia): un aggiornamento dei dati archeologici e archeometrici, en S. MENCHELLI, S. SANTORO, M. PASQUINUCCI y G. GUIDUCCI (eds.), LRCW3 Late Roman Coarse Wares, Cooking Wares and Amphorae in the Mediterranean: Archaeology and archaeometry. Comparison between western and eastern Mediterranean, BAR Int. Ser. 2185 (I), Oxford, vol. I, 33-56.

GARCÍA, I. y ROSSELLÓ, M., 1992, Las ánforas tardorromanas de Punta de l'Illa de Cullera, Estudios de Arqueología Ibérica y Romana, Homenaje a Enrique Pla Ballester, Servicio de Investigación Prehistórica (Serie de Trabajos Varios, 89), Valencia, 639-661.

GARCÍA, M. V. y VELASCO, V., 2019, El barrio artesanal de la insula II del Molinete, en J. M. NOGUERA, A. CÁNOVAS ALCARAZ, 
M. J. MADRID e I. MARTÍNEZ PERIS (eds.), Barrio del Foro Romano. Molinete, Cartagena. Santuario de Isis y Serapis (Insula II). Proyecto integral de recuperación y conservación/Roman Forum District. Molinete, Cartagena. Sanctuary of Isis and Serapis (Insula II). Recovery and conservation, Murcia, 113-119.

GUILLERMO, M., 2014, Cartagena Medieval, Cuadernos Monográficos Museo del Teatro Romano de Cartagena, Cartagena.

GUTIÉRREZ, S., 1998, Il confronto con la Hispania orientale: la ceramica nei secoli VI-VII, en L. SAGUI (a.c.), Ceramica in Italia: VI-VII secolo, Atti del Convegno in onore di John W. Hayes, (Roma, 11-13 maggio 1995), All'Insegna del Giglio, Florencia, vol. I, 549-567.

JIMÉNEZ, J. L., BURRIEL, J. M., SERRANO, M., SALAVERT, J. V. y ROSSELLÓ, M., 2005, L'Horta Vella (Bétera, València), de vil-la altimperial a establiment rural visigòtic, VI Reunió d'Arqueologia Cristiana Hispànica, València (2003), Barcelona, 305-316.

JONES, A. H. M., MARTINDALE, J. R. Y MORRIS, J., 1992, The Prosopography of the Later Roman Empire, vol. II, AD 395-527, Cambridge University Press, Cambridge.

KEAY, S., 1984, Late Roman Amphorae in the Western Mediterranean. A tipology and Economic Study: the Catalan Evidence, BAR Int. Ser. 196, 2 vols., Oxford.

LAÍZ, M. D. y RUIZ, E., 1988, Cerámicas de cocina de los siglos V-VII en Cartagena (C/ Orcel-Don Gil), Antigüedad y Cristianismo V, 265-301.

LECHUGA, M., 2000, Una aproximación a la circulación monetaria de época tardía en Cartagena: los hallazgos del teatro romano, $\checkmark$ Reunión de Arqueología Cristiana Hispánica (Cartagena 1998), Institut d'Estudis Catalans, Barcelona, 333-349.

MADRID, M. J., PAVÍA, M. y NOGUERA, J. M., 2015, Las termas del Puerto de Carthago Nova: un complejo augusteo de larga perduración, en J. LÓPEZ VILAR (ed.), Tarraco Biennal. Actes $2 n$ Congrés Internacional d'Arqueologia i Món Antic, August i les províncies occidentals. 2000 aniversari de la mort d'August, Tarragona, 26-29 de noviembre de 2014, Tarragona, vol. 2, 15-22.

MADRID, M. J. y VIZCAÍNO, J., 2009, La necrópolis de Carthago Spartaria. Dinámica de un espacio funerario entre el Bajo Imperio y la época bizantina, Contextos funeraris a la Mediterrània nordoccidental (segles V-VIII), Taula Rodona Sant Cugat del Vallès, del 1 al 3 de octubre de 2009, Gausac, 191-209.

MILÁ, S. y ARANA, R., 2007, Los materiales cerámicos del teatro romano de Cartagena: mineralogía y quimismo, Verdolay 10, 93-107.

MOLINA, J. y MATEO, D., 2018, The Roman amphorae average capacity (AC), Oxford Journal of Archaeology 37 (3), 299-311.

MORA, B., 2017, Las monedas procedentes de la factoría de salazones y su entorno, en M. CORRALES (ed.), Aportaciones a la Malaca tardorromana y bizantina. Excavaciones arqueológicas en la factoría de salazones del teatro romano de Málaga (siglos IV-VI d.C.), Sevilla, 167-200.

MORRISSON, C. y CHEYNET, J. C., 2002, Prices and Wages in the Byzantine World, en A. E. LAIOU (ed.), The Economic History of Byzantium: From the Seventh through the Fifteenth Century, Dumbarton Oaks Studies 39, 815-878.

MURCIA, A. J. y GUILLERMO, M., 2003, Cerámicas tardorromanas y altomedievales procedentes del Teatro Romano de Cartagena, en L. CABALLERO, P. MATEOS y M. RETUERCE (eds.), Cerámicas tardorromanas y altomedievales en la Península Ibérica, Anejos de Archivo Español de Arqueología XXVIII, Madrid, 169-223.

MURIALDO, G., 2001, I rapporti economici con l'area mediterranea e padana, en T. MANNONI y G. MURIALDO, (a.c.), S. Antonino: un insediamento fortificato nella Liguria bizantina, Bordighera, 301-307.

NACEF, J., 2007, Note préliminaire sur la production de la céramique antique dans la región de Salakta et Ksour Essef, en A. MRABET y J. REMESAL (eds.), In Africa et in Hispania: études sur l'huile africaine, Col.lecció Instrumenta 25, Universitat de Barcelona, Barcelona, 41-54. 
NAVARRO, I., MORA, B., SUÁREZ, J. y PIÑERO, D., 2017, Malaca: ciudad portuaria del Imperio Romano de Oriente, en M. CORRALES (ed.), Aportaciones a la Malaca tardorromana y bizantina. Excavaciones arqueológicas en la factoría de salazones del teatro romano de Málaga (siglos IV-VI d.C.), Sevilla, 201-271.

NOGUERA, J. M., ABASCAL, J. M. y MADRID, M. J., 2017, Un titulus pictus con titulatura imperial de Carthago Nova y puntualizaciones a la dinámica urbana de la ciudad a inicios del s. III d.C., Zephyrus LXXIX, enero-julio, 149-172.

NOGUERA, J. M., ABASCAL, J. M. y MADRID, M. J., 2018, Nuevas inscripciones romanas del Molinete (Cartagena) (campañas 2008-2017), Mastia. Revista del Museo Arqueológico de Cartagena 14, 63-101.

NOGUERA, J. M., CÁNOVAS, A., MADRID, M. J. y MARTÍNEZ, I. (eds.), 2016, Barrio del Foro Romano/Roman Forum District/Molinete/Cartagena. Proyecto integral de recuperación y conservación/ Recovery and Conservation (Premio Nacional de Restauración y Conservación de Bienes Culturales 2012)/(National Prize of Restoration and Conservation of Cultural Heritage 2012), Murcia.

NOGUERA, J.M., CÁNOVAS, A., MADRID, M. J. y MARTÍNEZ, I. (eds.), 2019, Santuario de Isis y Serapis (Insula II) Molinete/Cartagena. Barrio del Foro Romano. Proyecto integral de recuperación y conservación/Sanctuary of Isis and Serapis (Insula II). Roman Forum District. Recovery and conservation, Murcia.

NOGUERA, J. M. y MADRID, M. J. (eds.), 2010, Arx Hasdrubalis. La ciudad reencontrada. Arqueología en el cerro del Molinete/Cartagena, Madrid.

NOGUERA, J. M. y MADRID, M. J., 2014, Carthago Nova: fases e hitos de monumentalización urbana y arquitectónica (siglos III a.C.- III d.C., Espacio, Tiempo y Forma, I. Prehistoria y Arqueología 7, 13-60.

NOGUERA, J. M., VIZCAINO, J. y MADRID, M. J. (e.p.), Tiempos pasados y una edad nueva: la reactivación del opus africanum en Carthago Spartaria durante la etapa bizantina, en Reunión Científica Mímesis. Imitación de los modelos clásicos y nuevos valores semánticos en el mundo tardoantiguo y medieval, Universidad de Córdoba, 11 de diciembre de 2017.

OPRIȘ, I.C. y RAȚIU, A., 2016, An early Byzantine amphorae deposit from Capidava, Journal of Ancient History and Archeology 3.1, 24-42.

PECCI, A., CAU, M. A. y ROIG, J., 2019, Preliminary Organic Residue Analysis of Late Roman Amphorae from Eivissa (Balearic Islands, Spain), LRCW 7, $7^{\text {th }}$ International Conference on Late Roman Coarse Ware, Cooking Ware and Amphorae in the Mediterranean: Archaeology and Archaeometry. The End of Late Roman Pottery. The last centuries at the crossroads (València, 15 th $-19^{\text {th }}$ October 2019), Abstracts Book, 54.

PECCI, A., SALVINI, L., CIRELLI, E. y AUGENTI, A., 2010, Castor oil at Classe (Ravenna, Italy): Residue analysis of some late Roman amphorae coming from the port, en S. MENCHELLI, S. SANTORO, M. PASQUINUCCI Y G. GUIDUCCI (eds.), LRCW3. Late Roman Coarse Wares, Cooking Wares and Amphorae in the Mediterranean Archaeology and archaeometry. Comparison between western and eastern Mediterranean, BAR Int. Ser. 2185 (II), Oxford, 617-622.

PIERI, D., 2005, Le commerce du vin oriental à l'époque byzantine ( $V^{e}$-VII ${ }^{e}$ siècles). Le témoignage des amphores en Gaule, Beyrouth.

POCKLINGTON, R., 1986, Toponimia islámica del Campo de Cartagena, en J. MAS (dir.), Historia de Cartagena V, Murcia, 319-340.

RAMALLO, S. F., 2000, Carthago Spartaria, un núcleo bizantino en Hispania, en G. RIPOLL y J.M. GURT (eds.), Sedes regiae (ann. 400-800), Reial Acadèmia de Bones Lletres, Barcelona, 579-611.

RAMALLO, S. F., 2011, Carthago Nova. Puerto mediterráneo de Hispania, Murcia.

RAMALLO, S. F., MURCIA, A. J. y VIZCAINO, J., 2010, Carthago Nova y su espacio suburbano. Dinámicas de ocupación en la periferia de la ciuitas, en D. VAQUERIZO (ed.), Congreso Internacional Las áreas suburbanas en la ciudad histórica. Topografía, usos, función (Córdoba, 19-21 de octubre 2010), Córdoba, 211-254. 
RAMALLO, S. F., RUIZ, E. y BERROCAL, M. C., 1996, Contextos cerámicos de los siglos V-vII en Cartagena, Archivo Español de Arqueología 69, 143-146.

RAMALLO, S. F., RUIZ, E. y BERROCAL, M. C., 1997, Un contexto cerámico del primer cuarto del siglo VII en Cartagena, ArqueoMediterrania 2, Universitat de Barcelona, 203-228.

RAMALLO, S. F. y VIZCAÍNO, J., 2002, Bizantinos en Hispania. Un problema recurrente en la arqueología española, Archivo Español de Arqueología 75, 313-332.

RAMALLO, S. F. y VIZCAÍNO, J., 2011, Estructuras de almacenamiento en Carthago Noua y su territorium (s. III a.C.-VII d.C.), en J. ARCE y B. GOFFAUX (eds.), Horrea d'Hispanie et de la Méditerranée romaine, Collection de la Casa de Velázquez 125, Madrid, 225-263.

RAMÓN, J., 2008, La cerámica ebusitana en la Antigüedad Tardía, en D. BERNAL CASASOLA y A. RIBERA i LACOMBA (eds. científicos), Cerámicas hispanorromanas. Un estado de la cuestión. Rei Cretariae Romanae Fautores XXVI, Universidad de Cádiz, Cádiz, 563-583.

RAVEGNANI, G., 2004, I Bizantini e la guerra, Roma.

RAVEGNANI, G., 2007, Soldados de Bizancio en tiempos de Justiniano, Madrid (trad. al español del original, Boloña, 1988).

REYNOLDS, P., 2011, A $7^{\text {th }}$ century pottery deposit from Byzantine Carthago Spartaria (Cartagena, Spain), en M.A. CAU, P. REYNOLDS y M. BONIFAY (eds.), LRFW 1. Late Roman Fine Wares. Solving Problems of Typology and Chronology. $A$ review of the evidence, debate and new contexts, Roman and Late Antique Mediterranean Pottery, 1. Archaeopress, Oxford, 99-128.

REYNOLDS, P., 2015, Material culture and the economy in the age of Saint Isidore of Seville $\left(6^{\text {th }}\right.$ and $7^{\text {th }}$ centuries), Antiquité Tardive 23, 163-210.

RIERA, M., 2017, El monacat insular de la Mediterrània occidental. El monestir de Cabrera (Balears, segles V-VIII), Col-lecció Studia Archaeologiae Christianae, 1, Barcelona.
RIPOLL, G., 1996, Acerca de la supuesta frontera entre el Regnum Visigothorum y la Hispania bizantina, Pyrenae 27, 251-267.

RIZZO, E., 2015, Remarks on the logistics and infrastructure of the annona militaris in Eastern Mediterranean and Aegean areas, Antiquité Tardive 23, 287-302.

RODRÍGUEZ, F. y MACIAS, J. M., 2016, Un nuevo contexto cerámico de la segunda mitad del siglo vII d.C., en Tarracona (Tarraconensis, Regnum Visigothorum), en R. JÁRREGA y P. BERNI (eds.), Amphorae ex Hispania: paisajes de producción y consumo. III Congreso Internacional de la Sociedad de Estudios de la Cerámica Antigua (SECAH) - Ex Officina Hispana (Tarragona, 10-13 de diciembre de 2014), Tarragona, 936-952.

ROSSELLÓ, M. y RIBERA, A., 2005, Las cerámicas del siglo vir d.C. en Valentia (Hispania) y su entorno, Rei Cretariae Romanae Fautorum Acta 39, 155-164.

SÁNCHEZ DE PRADO, M. D. 2018, La vajilla de vidrio en el ámbito suroriental de la Hispania Romana. Comercio y producción entre los siglos I-VII d.C., Universitat d'Alacant, Alicante.

VALLEJO, M., 2012, Hispania y Bizancio. Una relación desconocida, Madrid.

VIZCAÍNO, J., 2008, Early Byzantine Lamellar Armour from Carthago Spartaria (Cartagena, Spain), Gladius. Estudios sobre armas antiguas, arte militar y vida cultural en Oriente y Occidente XXVIII, 195-210.

VIZCAÍNO, J., 2009, La presencia bizantina en Hispania (siglos VI-VII). La documentación arqueológica (Antigüedad y Cristianismo XXIV), Murcia.

VIZCAÍNO, J., 2013, Hispania y Oriente durante el período de ocupación bizantina (siglos VI-VII). La documentación arqueológica, en M.P. DE HOZ y G. MORA (eds.), El Oriente griego en la península Ibérica. Epigrafía e Historia, Real Academia de la Historia, Madrid, 281-305.

VIZCAÍNO, J., 2017, Vestido, comida y las demás cosas de la vida. Elementos metálicos de indumentaria y adorno personal en los contextos tardoantiguos de Carthago Spartaria, en I. BALDINI 
y A. L. MORELLI (eds.), Tempo e preziosi. Tecniche di datazione per l'oficeria, Ante Quem, Boloña, 49-76.

VIZCAÍNO, J., 2018, Ad pristinum decus. La metamorfosis urbana de Carthago Spartaria durante el siglo $\mathbf{v}$, en S. PANZRAM y L.

CALLEGARIN (eds.), Entre civitas y madina. El mundo de las ciudades en la Península Ibérica y en el norte de África (siglos IV-IX), Collection de la Casa de Velázquez 167, Madrid, 75-104.

VIZCAÍNO, J., 2019, ¿Epílogo o comienzo? La ocupación bizantina en el antiguo santuario de Isis, en J. M. NOGUERA, A. CÁNOVAS ALCARAZ, M. J. MADRID e I. MARTÍNEZ PERIS (eds.), Barrio del Foro Romano. Molinete, Cartagena. Santuario de Isis y Serapis (Insula II). Proyecto integral de recuperación y conservación/Roman Forum District. Molinete, Cartagena. Sanctuary of Isis and Serapis (Insula II). Recovery and conservation, Murcia, 123-129.

VIZCAÍNO, J., NOGUERA, J.M. y MADRID, M. J., 2019a, Rediviva moenia. Nuevos datos sobre las murallas de Carthago Spartaria en época bizantina, en J. M. MACÍAS, A. RIBERA y M. ROSSELLÓ (eds.), Recintes fortificats en época visigoda: Història, Arquitectura i Territori, Sèria Trama, ICAC, Tarragona.

VIZCAÍNO, J., NOGUERA, J. M. y MADRID, M. J., 2019b, Del motivo a la imagen. Acerca de la iconografía cristiana en Terra Sigillata Africana D empleada en época bizantina. Una visión desde el barrio de la arx Hasdrubalis de Carthago Spartaria (Cartagena), en Actes del 4t Congrés Internacional d'Arqueologia i Món Antic, VII Reunió d'Arqueologia Cristiana Hispànica: El cristianisme en l'Antiguitat Tardana. Noves perspectives, Tarragona.

VIZCAINO, J., NOGUERA, J. M. y MADRID, M. J. (e.p.), Nuevos datos sobre la ocupación bizantina en Carthago Spartaria: el barrio de la antigua arx Hasdrubalis, en Reunión científica Bizancio en Ceuta. Arqueología y comercio en el Fretum Gaditanum (siglos VI-VII d.C.) (9-10 de marzo de 2018), Ceuta.

VIZCAÍNO, J. y PÉREZ, I., 2008, Ungüentarios bizantinos con sello epigráfico en Carthago Spartaria, Archivo Español de Arqueología 81, $151-176$. 